This document was prepared in conjunction with work accomplished under Contract No. DE-AC09-96SR18500 with the U. S. Department of Energy.

\title{
DISCLAIMER
}

This report was prepared as an account of work sponsored by an agency of the United States Government. Neither the United States Government nor any agency thereof, nor any of their employees, makes any warranty, express or implied, or assumes any legal liability or responsibility for the accuracy, completeness, or usefulness of any information, apparatus, product or process disclosed, or represents that its use would not infringe privately owned rights. Reference herein to any specific commercial product, process or service by trade name, trademark, manufacturer, or otherwise does not necessarily constitute or imply its endorsement, recommendation, or favoring by the United States Government or any agency thereof. The views and opinions of authors expressed herein do not necessarily state or reflect those of the United States Government or any agency thereof.

This report has been reproduced directly from the best available copy.

Available for sale to the public, in paper, from: U.S. Department of Commerce, National Technical Information Service, 5285 Port Royal Road, Springfield, VA 22161, phone: (800) 553-6847, fax: (703) 605-6900

email: orders@ntis.fedworld.gov

online ordering: http://www.ntis.gov/help/index.asp

Available electronically at http://www.osti.gov/bridge

Available for a processing fee to U.S. Department of Energy and its contractors, in paper, from: U.S. Department of Energy, Office of Scientific and Technical Information, P.O. Box 62, Oak Ridge, TN 37831-0062,

phone: (865)576-8401,

fax: (865)576-5728

email: $\underline{\text { reports@ adonis.osti.gov }}$ 
WSRC-TR-2001-00109, Revision 1

SRT-RPP-2001-00026, Revision 1

Formerly BNF-003-98-0252

\section{Results from Analyses of a Hanford Envelope A Radioactive Glass Waste Form}

Westinghouse Savannah River Company

Savannah River Site

Aiken, SC 29808

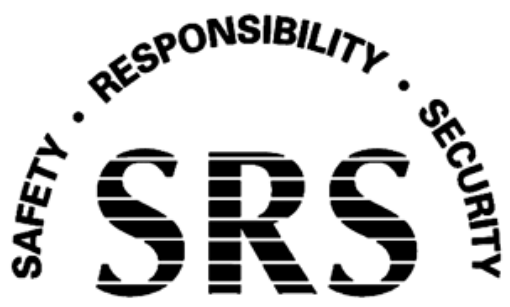

SAVANNAH RIVER SITE

Prepared for the U.S. Department of Energy under Contract No. DE-AC09-96SR18500 
WSRC-TR-2001-00109, Revision 1

SRT-RPP-2001-00026, Revision 1

Formerly BNF-003-98-0252

KEYWORDS:

Hanford River Protection Project

Vitrification, Low-Activity Waste,

Regulatory, AN-103

\section{Results from Analyses of a Hanford Envelope A Radioactive Glass Waste Form}

SAVANNAH RIVER TECHNOLOGY CENTER

D. Ferrara

R. Ray

W. Kubilius

C. Crawford

Publication Date: September 12, 2001

Westinghouse Savannah River Company

Savannah River Site

Aiken, SC 29808

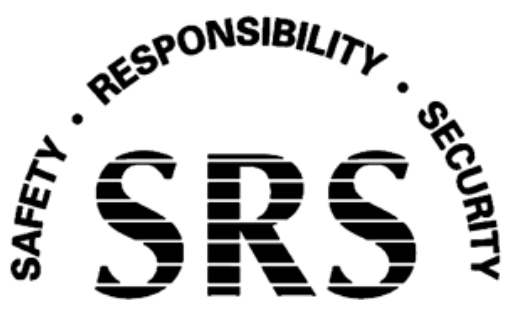

SAVANNAH RIVER SITE

Prepared for the U.S. Department of Energy under Contract No. DE-AC09-96SR18500 


\section{WSRC-TR-2001-00109, Revision 1 \\ SRT-RPP-2001-00026, Revision 1 \\ Formerly BNF-003-98-0252}

\section{ACKNOWLEDGEMENTS}

The results presented in this report are the product of the efforts of a task team made up of over twenty individuals at the Savannah River Site, Babcock and Wilcox, Southwest Research Institute, and Oak Ridge National Laboratory. The success of this program was only possible because of the ability of these individuals to work as a team. In particular, the authors would like to thank personnel at Babcock and Wilcox and Southwest Research Institute. Our primary contacts were Bill Stagg, Paul Macek and Les Hawthorne at Babcock and Wilcox, and Chee-Kai Tan at Southwest Research Institute. In addition, we are thankful for the extra effort that was put into the sample preparation and shipment by Susan Jurgensen, Sarah Brown, Sherry Vissage, and Beverly Burch.

\section{Contents}

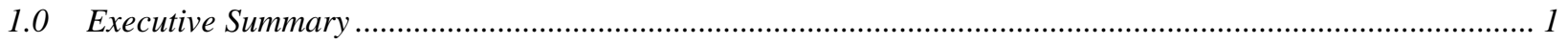

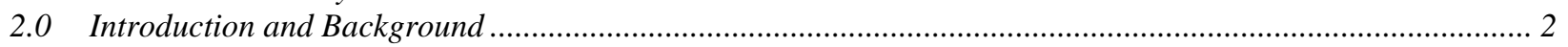

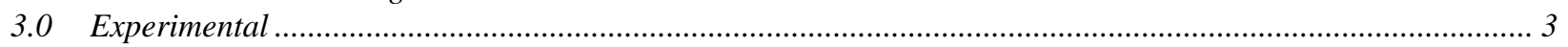

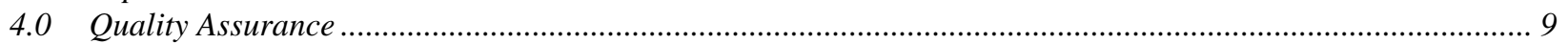

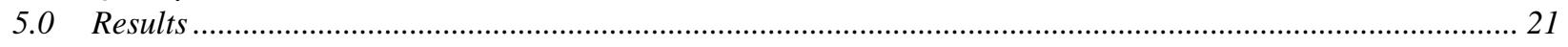

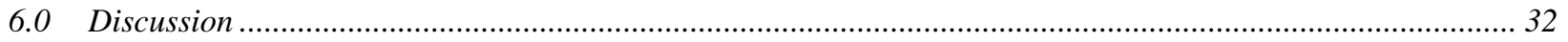

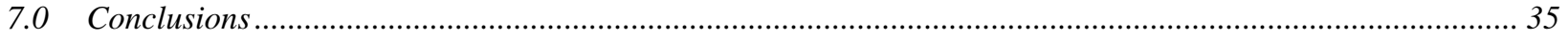

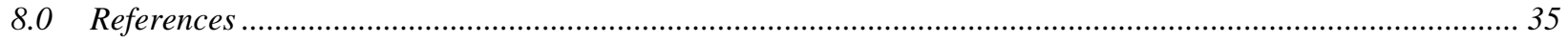

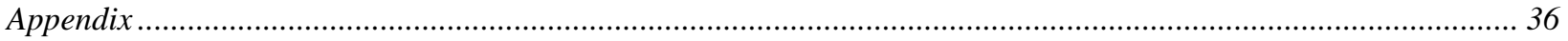

\section{List of Tables}

Table 3.1. Summary of Sample, Blank, and Standard Preparation and Analysis Methods.................................... 5

Table 3.2. Preparation and Analysis Methods for Dissolved Glass Samples .................................................... 6

Table 4.1. Summary of QA Results for Cyanide and Dangerous Waste Characteristics..................................... 10

Table 4.2. Summary of QA Results for Toxicity Characteristic Leaching Procedure............................................ 11

Table 4.3. Summary of QA Results for Characterizing the Envelope A Waste Form .............................................. 14

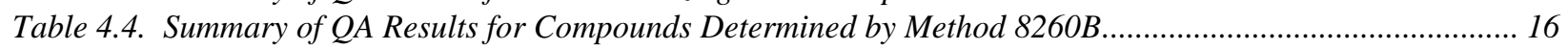

Table 4.5. Summary of QA Results for Organic Compounds Determined by IC .................................................... 17

Table 4.6. Summary of QA Results for Semivolatile Organic Compounds Analyses............................................. 18

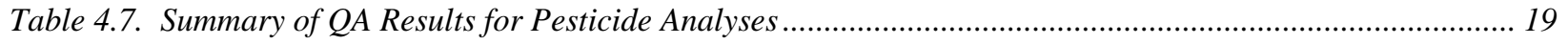

Table 4.8. Summary of QA Results for Polychlorinated Biphenyl Analyses...................................................... 20

Table 4.9 Summary of LCS Recoveries for Radionuclide Analyses .............................................................. 21

Table 5.1. Analyses to Determine if Samples Have Dangerous Waste Characteristics........................................ 23

Table 5.2. Results from TCLP, Toxicity Characteristic Leaching Procedure....................................................... 23

Table 5.3. Results $(\mathrm{mg} / \mathrm{kg})$ in Support of Characterizing Envelope A Glass Waste Form Samples.......................... 25

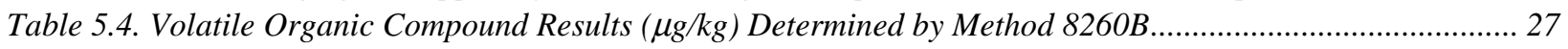

Table 5.5. Results $(\mathrm{mg} / \mathrm{kg})$ of Volatile Organic Compounds Determined by IC ................................................... 28

Table 5.6. Results $(\mu \mathrm{g} / \mathrm{kg})$ of Semivolatile Analyses ......................................................................................... 29

Table 5.7. Results $(\mu \mathrm{g} / \mathrm{kg})$ of Pesticide Analyses ....................................................................................................... 30

Table 5.8. Results $(\mu \mathrm{g} / \mathrm{kg})$ of Polychlorinated Biphenyls (PCBs) Analyses ............................................................. 30

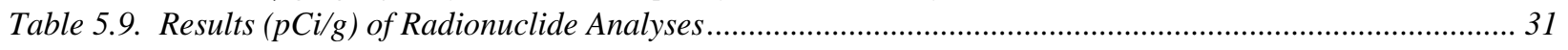

Table 5.10. Results from Density $(\mathrm{g} / \mathrm{cc})$ Determination of Envelope A Glass Samples ......................................... 32 


\section{WSRC-TR-2001-00109, Revision 1 \\ SRT-RPP-2001-00026, Revision 1 \\ Formerly BNF-003-98-0252}

\subsection{Executive Summary}

A supernate sample (Envelope A) from Hanford Waste Tank AN-103 was shipped to the Savannah River Site (SRS) where the sample was pretreated to remove the majority of the radionuclides and was vitrified. Methods used in the pretreatment and vitrification were laboratory-scale versions of the methods proposed by River Protection Project (RPP) personnel for immobilization of Hanford tank waste. Samples of the resulting glass waste form were collected, treated and analyzed according to EPA SW-846 protocol.

Results indicated that the composition of the glass waste form was close to the target composition. In addition, the concentration of alpha emitting radionuclides $\left(2.4 \times 10^{2} \mathrm{pCi} / \mathrm{g}\right) \mathrm{was}$ orders of magnitude below the value at which the waste form would need to be handled as Transuranic (TRU) waste. Cesium-137 was the predominant radionuclide and was present at $\left(1.2 \times 10^{6} \mathrm{pCi} / \mathrm{g}\right)$.

Analyses showed the waste form met applicable limits for target analytes specified. These analyses included cyanide, RCRA metal, dioxin and furan, volatile organic compound and semivolatile organic compound content, and RCRA metal leachability. Results from the Toxicity Characteristic Leaching Procedure (TCLP) showed the waste form met Universal Treatment Standard (UTS) for all target analytes. Detection limits for thallium were too high to determine whether this element met the UTS limit. Thallium was not one of the specified target analytes.

Samples were characterized for over 150 organic analytes. Four volatile organic compounds were detected in the samples at concentrations (between 3 and $7 \mu \mathrm{g} / \mathrm{kg}$ ) that were below what is typically considered quantitative (less than 10 times the detection limit). Except for acetone, these volatile organics were detected at similar concentrations in one of the field blanks. These volatile organic compounds are thought to have been present as a result of laboratory contamination.

Two dioxins and one furan were detected at very low concentrations (between 0.3 and $5 \mathrm{ng} / \mathrm{kg}$ ) in the samples but were detected at similar or higher levels in the field blanks. In addition, two unidentified organic compounds were detected in all samples and blanks analyzed for semivolatile organic compounds. These organic compounds are thought to have been present as a result of laboratory contamination. Although three semivolatile organic analytes could not be measured directly, results for the other semivolatile organic analytes suggest that these three compounds also were not present in the glass waste form at detectable concentrations. 


\section{WSRC-TR-2001-00109, Revision 1 \\ SRT-RPP-2001-00026, Revision 1 \\ Formerly BNF-003-98-0252}

\subsection{Introduction and Background}

As part of the River Protection Project (RPP), the United States Department of Energy (DOE) is developing a process for treating and immobilizing radioactive waste that is being stored in tanks at the DOE site in Hanford Washington.

The Savannah River Technology Center (SRTC) has been asked to perform demonstrations of the proposed process using nonradioactive samples (waste stream simulants) and radioactive samples (from the Hanford Tank Farm). As part of these demonstrations, SRTC is to have key samples analyzed according to "regulatory" protocol. ${ }^{1,2,3}$ One set of samples was from an Envelope A glass waste form produced from pretreatment and vitrification of supernate taken from Hanford Tank AN-103. This report is a summary of these regulatory analysis results.

The results in this report are from analysis of a glass waste form that was produced by six furnace vitrification tests. Three of these tests were performed with a nonradioactive simulant material to produce vitrification "process blanks". The remaining three tests were performed with the pretreated Envelope A supernate sample. The details surrounding these furnace demonstrations have been described elsewhere. ${ }^{4}$

SRTC personnel collected samples of the glass waste form. SRTC personnel also performed some of the sample preparation. With the exception of the volatile organic analyses and the dioxin and furan analyses, BWXT performed the sample analyses. Southwest Research Institute (SwRI) performed the volatile organic analyses and the dioxin and furan analyses. Both laboratories routinely perform analyses according to the EPA protocol specified for these samples.

Results from all regulatory analyses of the Envelope A glass waste form are presented in this report. Although some of the process blank and field blank results have also been presented here, a complete presentation of results from the process blanks, field blanks, trip blanks, laboratory method blanks, and standards have not been included here. Instead, the five volume data package is being issued independently. ${ }^{5}$ The table of contents from this data package has been included as an appendix to this report.

This report has been organized to make it as compatible as possible with the requests made by RPP personnel. ${ }^{1,2}$ Chapter 3.0 Experimental has been organized chronologically into sections describing the sample collection, preparation and analysis. Chapter 5.0 Results has been organized into a separate section for each of the tables in Reference 1. 


\section{WSRC-TR-2001-00109, Revision 1 \\ SRT-RPP-2001-00026, Revision 1 \\ Formerly BNF-003-98-0252}

Revision 1 of this report is being issued primarily to provide information not included in Revision 0 and to provide clarification of some information that was included in Revision 0 . The most significant change that was made during the revision was the incorporation of quality assurance and quality control results. Specifically, Revision 1 incorporated the following changes:

-A Table of Contents and List of Tables was included (Page iv).

-The format was changed to the standard SRS technical report format (all pages)

-"Formerly BNF-003-98-0252" and "Revision 1" were added to the headers (all pages).

-The document issue date was changed to reflect issue date for Revision 1 (Page ii).

-Changes were made to the authors and responsible management (Pages ii and iii).

-Editorial changes were made (throughout).

-Changes were made to reflect the current RPP contractor (throughout).

-Additional detail was included on the generation of field blanks (Page 4).

-Additional information was included in 1.0 Executive Summary (Page 1).

-Additional discussion was included for Tables 3.1 and 3.2 (Pages 5 and 6).

-Method referenced in Table 3.2 was changed from "15305" to "3015" (Page 6).

-Requirement for acid digestion of TCLP extracts was referenced (Page 6).

-Quality assurance and quality control detail was added (Pages 7, 8, and 9-20).

-Additional discussion was provided on the density results (Page 9).

-References were given for definition of the estimated quantitative limit (Page 21).

-Additional discussion was included on TCLP and metal analyses (Pages 22).

-Units $(\mu \mathrm{g} / \mathrm{L})$ were designated in Table 5.2 rather than in the table title (Page 24).

-An explanation of the Table 4.3 column headings was given (Page 24).

-Additional detail was included on the detection limits in Table 4.3 (Page 24).

-Additional detail was included on application of the CLP 5x rule (Pages 33 and 34).

-Addition detail was included on the nontarget analytes that were detected (Page 34).

-Inaccurate reference to Low-Level Radioactive Waste was deleted (Page 34).

-Paragraphs were moved to accommodate page breaks and tables (throughout).

\subsection{Experimental}

This chapter is a description of the methods used to collect, prepare, and analyze the samples. Descriptions of the sample collection and sample preparation methods have been organized according to how the samples were generated. Sample analyses have been presented in the same order as the analytes listed in Tables 1 through 5 of Reference 1. 


\section{WSRC-TR-2001-00109, Revision 1 \\ SRT-RPP-2001-00026, Revision 1 \\ Formerly BNF-003-98-0252}

\section{A. Sample Collection}

Four "supersamples" of glass waste form material were collected from six furnace tests. The supersamples were

-Nonradioactive (process blank) samples for volatile organic compound analysis.

-Envelope A samples for volatile organic compound analysis.

-Nonradioactive (process blank) samples to be ground prior to analysis.

-Envelope A samples to be ground prior to analysis.

The supersamples collected for volatile organic compound analysis were used to meet some of the characterization needs specified in Reference 1 for supporting a delisting petition and for supporting permitting. The other supersamples were used for the remainder of the delisting and permitting analyses and all analyses specified for tank waste, radionuclide, and physical property characterization.

Sampling of these waste forms was performed between 1 week and 1 month after the glass waste forms were produced. The sampling process was a simple transfer of the glass waste form materials from their storage containers to a glass jar that had been certified as clean. The storage containers were either another certified clean glass jar or the crucible in which the glass was made.

Immediately after collecting the glass waste form samples, field blanks were collected. The field blanks were reagent grade sand generated in the same fashion as the waste form supersamples. To generate the field blanks, sand was transferred to sample containers in the same location and immediately before sampling of the glass waste forms. For the process blank and Envelope A supersamples that were used for volatile organic compounds characterization, the supersamples were collected on different days. Therefore, a separate field blank was generated for each of these supersamples. In addition, ASTM Type II water was used for trip blanks.

\section{B. Sample Preparation}

Each supersample was subjected to size reduction and divided into samples for preparation and analysis. Table 3.1 is a summary of the samples, blanks, and standards and of the preparation and analysis methods. For each sample, some of the sample preparation was performed by SRS and the remainder was performed by one of the subcontractors prior to analysis.

Size reduction was performed at SRS. For volatile organic analysis samples and blanks, an agate mortar and pestle were used to break the material into pieces that fit into a standard fortymilliliter vial. Samples were collected in a fashion that would be consistent with Method 5035 treatment and Method 8260B analysis. For the other supersamples, the agate mortar and pestle were used to grind samples and blanks into particles with diameters of less than $0.9 \mathrm{~cm}$. Some of 


\section{WSRC-TR-2001-00109, Revision 1 \\ SRT-RPP-2001-00026, Revision 1 \\ Formerly BNF-003-98-0252}

this material was ground further ${ }^{4}$ and dissolved by either an acid dissolution, a sodium peroxide fusion with an acid uptake, or a sodium peroxide fusion with a water uptake.

Table 3.1. Summary of Sample, Blank, and Standard Preparation and Analysis Methods

\begin{tabular}{|c|c|c|c|c|c|c|c|c|}
\hline & Samples & \multicolumn{3}{|c|}{ Blanks } & Standards & \multicolumn{2}{|c|}{ Preparation } & Analysis $^{+}$ \\
\hline & & Proc & Field & Trip & & SRS & Lab. $^{+}$ & \\
\hline Misc. Volatiles* & 4 & 4 & 2 & 1 & - & Break & 5035 & $8260 \mathrm{~B}$ \\
\hline IC - Organics* & 4 & 4 & 2 & 1 & - & Break & Extract & Mod. 9056 \\
\hline Methanol* & 4 & 4 & 2 & 1 & - & Break & Extract & $8015 \mathrm{~B}$ \\
\hline Semivolatiles & 2 & 2 & 1 & - & - & Grind & 3550B & $8270 \mathrm{C}$ \\
\hline Pesticide\&PCB & 2 & 2 & 1 & - & - & Grind & $3550 \mathrm{~B}$ & 8081,8082 \\
\hline Dioxin\&Furan & 2 & 2 & 1 & - & - & Grind & 8290 & 8290 \\
\hline TCLP & 1 & 1 & 1 & - & 1 & Grind & 1311 & $3015,6010 \mathrm{~B}$ \\
\hline Miscellaneous & 2 & 2 & 1 & - & - & Grind & $* *$ & $* *$ \\
\hline Acid Dissolution & 2 & 2 & 1 & - & 2 & Dissolve & Table 3.2 & Table 3.2 \\
\hline Fusion \& Acid & 2 & 2 & 1 & - & 2 & Dissolve & Table 3.2 & Table 3.2 \\
\hline Fusion $\& \mathrm{H}_{2} \mathrm{O}$ & 2 & 2 & 1 & - & 2 & Dissolve & Table 3.2 & Table 3.2 \\
\hline
\end{tabular}

*Samples prepared by breaking of supersamples that were produced for volatile organic analyses.

**Samples prepared and analyzed for cyanide, density, oxalate, ignitability, ammonia, and total halides.

${ }^{+}$Performed by Southwest Research Institute (SwRI) or Babcock and Wilcox Technologies, Inc (BWXT).

The resulting samples were sent to one of the subcontractor laboratories where additional pretreatment was performed as shown in Table 3.1 (column labeled "Lab."). SwRI was responsible for the samples that were analyzed for miscellaneous volatile organics, volatile organics by IC, methanol, and dioxins and furans. The extraction indicated in Table 3.1 for the IC and methanol samples was a water extraction. The other analyses were performed by BWXT.

One set of samples (identified as "Miscellaneous" in Table 3.1) was characterized for cyanide, density, oxalate, ignitability, ammonia, and total halides. For density, ignitability and total halide analyses, no preparation was necessary. Prior to the other analyses, the following preparation steps were performed:

-Cyanide: EPA SW-846 Method 9010B

-Oxalate: Hot Water Leach

-Ammonia: Sample Digestion 


\section{Sample Analysis}

The title of each subsection in this section was taken from the corresponding table in Reference 1. Titles are not meant to suggest that the designated activities are underway. For example, Subsection 1 is titled "Analysis to Support Delisting Petition." At this time, the authors are not involved in efforts toward delisting the low-activity waste forms from the Hanford High-Level Waste tanks.

\section{Analysis to Support Delisting Petition}

Analyses described in this subsection were performed on the last six sets of samples listed in Table 3.1. The methods used for most of the analyses have been given in Table 3.1. For the metals, anions and radionuclides analyses, the samples were dissolved at SRS prior to shipment to BWXT for analysis. The analytical methods have been given in Table 3.2 along with the preparation and analysis methods used to characterize the samples that were dissolved at SRS prior to shipment to BWXT.

Table 3.2. Preparation and Analysis Methods for Dissolved Glass Samples

\begin{tabular}{|c|c||c|c|}
\hline & Samples & Preparation & Analysis \\
\hline \hline & & & $6010 \mathrm{~B}$ \\
\hline ICP-ES & Acid, Fusion \& Acid & 3015 & $7470 \mathrm{~A}$ \\
\hline CV-Hg & Acid, Fusion \& Acid & - & Gamma PHA \\
\hline Gamma & Acid, Fusion \& Acid & - & Alpha PHA \\
\hline Transuranics & Acid, Fusion \& Acid & Separation & Alpha PHA \\
\hline Uranium & Acid, Fusion \& Acid & Separation & Scintillation \\
\hline C-14/H-3 & Acid, Fusion \& Acid & Oxidation & Method 9310 \\
\hline Alpha/Beta & Acid, Fusion \& Acid & - & Scintillation \\
\hline Sr-90 & Acid, Fusion \& Acid & Separation & Gamma PHA \\
\hline I-129 & Acid, Fusion \& Acid & Separation & Scintillation \\
\hline Se-79 & Acid, Fusion \& Acid & Separation & Scintillation \\
\hline Tc-99 & Acid, Fusion \& Acid & Separation & Method 9056 \\
\hline Anions & Fusion \& Water & 25:1 Dilution & . \\
\hline
\end{tabular}

Analytes were bromide, chloride, fluoride, nitrate, nitrite, phosphate, and sulfate.

Standard methods were used to characterize the samples for the other analytes. For cyanide and ignitability, the set of samples designated for miscellaneous analyses was used. Cyanide was determined using Method 9014. Ignitability was measured using Method 1030 modified to accommodate a smaller sample size. The TCLP leachates were acidified-digested as required by the TCLP method (Step 7.2.14) prior to analysis. Except for the sample analyzed for mercury, Method 3015 was used to acid-digest the samples. The resulting digested extract was analyzed using Method 6010B. For mercury, the sample was acid-digested and analyzed using Method 7470A. 


\section{WSRC-TR-2001-00109, Revision 1 \\ SRT-RPP-2001-00026, Revision 1 \\ Formerly BNF-003-98-0252}

In addition, dioxins and furans were measured according to EPA SW-846 Method 8290. This analytical procedure had been implemented as a SwRI standard operating procedure (SOP). One furan (OCDF) and two dioxins (HpCDD and OCDD) were detected in all samples and blanks. In addition, one of the process blanks was determined to have been contaminated with OCDD from glassware that was determined to have been used in other Method 8290 analyses. All values have been included, but these results should be considered to be the maximum concentrations that could be present in the samples.

\section{Analysis to Support Characterization of Glass Waste Form Samples}

These analyses were performed on the last three sets of samples listed in Table 3.1. The cyanide and metals analyses have been discussed in Subsection 3.C.1. Analysis to Support Delisting Petition. The other analyses that were performed to support characterization of the tank waste samples were Method 9056 analysis for the anions, determination of ammonia, and Method 9020B for total halide determination.

Ammonium was determined using an ion-selective electrode technique. This was consistent with discussions held with RPP personnel and was consistent with the task plan. A method blank was not analyzed along with the samples. Although not required, a trip blank was sent along with the samples that were analyzed for ammonium. Ammonium was determined in the trip blank. The value measured in the trip blank was used as the detection limit for these results. All other quality control and quality assurance requirements were met as specified in Reference 2 .

\section{Analysis to Support Permitting}

Analyses described in this subsection were performed on the first six sets of samples listed in Table 3.1. These analyses consist of all the organic compound analyses except the dioxins and furans. All methods used for these analyses had been discussed with RPP personnel prior to the analyses. Except for determination of methanol by EPA SW-846 Method 8015, all methods had also been incorporated in the task plan.

As indicated in Table 3.1, after preparation of samples by EPA SW-846 Method 5035, most of the volatile organic compounds specified in Reference 1 were determined by SwRI using EPA SW-846 Method 8260B. For volatile organic compound analyses, surrogate recoveries were out of specification for three samples and one process blank. Low level concentrations were detected for 2-methyl-2-propanol, acetone, and toluene in these samples. In addition, tetrasiloxane was detected in the trip blank as well as the laboratory's method blank. Tetrasiloxane is a component of vacuum grease and is common in laboratory environments. The measured concentrations have been reported for these analytes; however, because the accuracy of the results is questionable (expected to be biased high due to laboratory contamination), these results should be considered to be the maximum concentrations that could be present in the samples. 


\section{WSRC-TR-2001-00109, Revision 1 \\ SRT-RPP-2001-00026, Revision 1 \\ Formerly BNF-003-98-0252}

To determine the concentration of formate and acetate, SwRI used a modified version of Method 9056 after extracting the samples with water overnight. The modified Method 9056 was a SwRI standard operating procedure (SOP) in which the standard carbonate/bicarbonate eluant was replaced by a sodium borate eluant. This allowed the acetate and formate to be determined separately. Matrix spike and matrix spike duplicate analyses were easily within the specified ranges for these samples. Triethylamine was determined using a Dionex CS14 column and a methane/sulfonic acid/acetonitrile eluant. This analytical method had been implemented at SwRI as a SOP.

After performing this same extraction on the methanol samples, SwRI determined the methanol concentrations using EPA SW-846 Method 8015. The SwRI SOP followed the EPA SW-846 method except that it was modified to include methanol as the target analyte. Containment of the Envelope A field blank appears to have been compromised since this field blank was described by SwRI as being an aqueous/solid mixture. The field blank should have been reagent grade sand. Because the integrity of the samples was not compromised, because the sample analyses met the required quality assurance requirements and because methanol concentrations in the samples were below the analytical method detection limits, the reported detection limits for methanol should be considered valid (results in subsection 5.C.1.c. Methanol).

As indicated in Table 3.1, after preparing the sample using EPA SW-846 Method 3550B, BWXT used EPA SW-846 Method 8270C to analyze samples for semivolatile organic compounds. Two nontarget compounds were detected in the samples, the process blanks, the field blanks, and in the laboratory's method blanks. The identity of the compounds was not determined. The concentrations reported for these unidentified species should be considered to be the maximum concentration that could be present. Because these compounds were present in all quality control samples, they should be considered to be contaminants. These compounds are being reported here as directed by the RPP customer.

Because EPA Method 3550B was used as a preparation step for both the pesticides and PCB analyses, a single sample was extracted, and the resulting extraction liquid was used for both analyses. Although the same method was also used for analysis of semivolatile compounds, a different extraction fluid was used for preparation of the samples for semivolatile organic compound analyses.

After extraction of the pesticide and PCB samples using EPA SW-846 Method 3550B, BWXT used a portion of the resulting extraction liquid to analyze for pesticides by EPA SW-846 Method 8081 and another portion to analyze for PCBs by EPA SW-846 Method 8082. All calibrations, calibration checks and recoveries were within specified limits for both of these analyses.

\section{Radionuclide Analysis}

The methods have been summarized in Table 3.2. Detection limits for selenium-79 have been included as they were reported from the laboratory although recoveries for this species were not 


\section{WSRC-TR-2001-00109, Revision 1 \\ SRT-RPP-2001-00026, Revision 1 \\ Formerly BNF-003-98-0252}

within the range specified in Reference 2 . Detection limits for carbon-14 were very high because of interferences. The values given in this report for carbon-14 have been adjusted to account for these interferences.

\section{Determination of Physical Properties}

Pycnometry was used to determine the density of the glass waste form samples. These analyses were performed on the set of samples labeled as "Miscellaneous" in Table 3.1. Size reduction on these samples was limited to that which was necessary to provide a waste form with particles less than $0.9-\mathrm{cm}$ diameters. Although this may have reduced the bulk density somewhat, the effect was expected to have been less than measurable and in any case would have caused the measured bulk density to be biased high by less than $10 \%$.

\subsection{Quality Assurance}

This chapter is a summary of the quality assurance aspects of these analyses. Reference 5 is the data package for these analyses and includes results from all samples and quality assurance measures. An abbreviated table of contents for Reference 5 has been included in the Appendix to this report. Except where noted, EPA SW-846 protocol was implemented through SOPs that followed EPA SW-846 guidance. Deviations from EPA SW-846 are discussed in this chapter. For applications that require strict adherence to the quality control limits specified, additional samples would need to be analyzed to provide the few results that deviated from these quality control limits.

\section{A. Analysis to Support Delisting Petition}

The first analyses to be discussed in Chapter 5.0 Results will be analyses that were performed to support delisting. These results are discussed in three groups, cyanide analyses, dangerous waste characteristics, and TCLP. Although field blanks and process blanks are discussed in this section, the results from the analyses of these blanks are presented along with the sample analyses in Chapter 5.0 Results.

\section{Miscellaneous}

Cyanide analyses were made on a water leachate according to EPA SW-846 Methods 9010B and 9014. The SOP was written to allow for a smaller leachate volume than SW-846 (61 instead of 500 milliliters). Although no range was specified for cyanide recovery, laboratory control spike (LCS), matrix spike (MS), and matrix spike duplicate (MSD) recoveries were within the specified range for metals (75 to 125 percent) as was the matrix spike precision (relative deviation less than 20 percent). These results and the calibration check sample results have been included in Table 4.1. 
WSRC-TR-2001-00109, Revision 1

SRT-RPP-2001-00026, Revision 1

Formerly BNF-003-98-0252

Table 4.1. Summary of QA Results for Cyanide and Dangerous Waste Characteristics

\begin{tabular}{|c|c|c|c|c|c|c|}
\hline Characteristic & Analyte & \multicolumn{4}{|c|}{ Recovery } & \multirow[t]{2}{*}{ Calibration } \\
\hline & & LCS & MS & MSD & Rel. Deviation & \\
\hline Cyanide (\%) & $\mathrm{CN}^{-}$ & 102 & 86 & 90 & 4.5 & 96-100 \\
\hline \multirow{9}{*}{$\begin{array}{c}\text { Total Metals } \\
(\%)\end{array}$} & As & 90.6 & 90.7 & 90.9 & 0.2 & $102-103$ \\
\hline & $\mathrm{Ba}$ & 93.5 & 92.9 & 92.7 & 0.2 & $98.1-98.7$ \\
\hline & $\mathrm{Cd}$ & 95.4 & 93.6 & 95.1 & 1.6 & $100-102$ \\
\hline & $\mathrm{Cr}$ & 98.6 & 97.1 & 98.7 & 1.6 & 104-106 \\
\hline & $\mathrm{Pb}$ & 82.6 & 91.0 & 93.9 & 3.1 & $100-103$ \\
\hline & $\mathrm{Se}$ & 109 & 98.1 & 98.4 & 0.3 & 101-103 \\
\hline & $\mathrm{Ag}$ & 93.4 & 4.5 & 5.4 & 18.2 & $100-102$ \\
\hline & $\mathrm{Ni}$ & 99.3 & 99.0 & 99.7 & 0.7 & $103-106$ \\
\hline & $\mathrm{Hg}$ & 99.5 & 107 & 111 & 3.7 & $87.4-94.6$ \\
\hline \multirow{17}{*}{$\begin{array}{c}\text { Dioxins \& Furans } \\
(\%)\end{array}$} & 2,3,7,8-TCDD & & 77.8 & 81.6 & 4.8 & $79.4-110$ \\
\hline & $1,2,3,7,8-\mathrm{PeCDD}$ & & 76.3 & 83.3 & 8.8 & $88.1-111$ \\
\hline & $1,2,3,4,7,8-\mathrm{HxCDD}$ & & 111 & 112 & 0.9 & - \\
\hline & $1,2,3,6,7,8-\mathrm{HxCDD}$ & & 93.1 & 91.9 & 1.3 & $84.6-112$ \\
\hline & $1,2,3,7,8,9-\mathrm{HxCDD}$ & & 86.4 & 90.2 & 4.3 & - \\
\hline & $1,2,3,4,6,7,8-\mathrm{HpCDD}$ & & 77.6 & 77.3 & 0.4 & $88.4-95.8$ \\
\hline & OCDD & & - & - & - & $81.4-89.0$ \\
\hline & 2,3,7,8-TCDF & & 103 & 113 & 9.3 & $78.7-117.5$ \\
\hline & $1,2,3,7,8-\mathrm{PeCDF}$ & & 96.1 & 95.7 & 0.4 & $88.2-103$ \\
\hline & $2,3,4,7,8-\mathrm{PeCDF}$ & & 96.3 & 92.2 & 4.4 & - \\
\hline & $1,2,3,4,7,8-\mathrm{HxCDF}$ & & 96.1 & 95.1 & 1.0 & $87.1-104$ \\
\hline & $1,2,3,6,7,8-\mathrm{HxCDF}$ & & 95.5 & 97.9 & 2.5 & - \\
\hline & $1,2,3,7,8,9-\mathrm{HxCDF}$ & & 79.4 & 85.4 & 7.3 & - \\
\hline & $2,3,4,6,7,8-\mathrm{HxCDF}$ & & 98.1 & 100 & 1.9 & - \\
\hline & $1,2,3,4,6,7,8-\mathrm{HpCDF}$ & & 97.2 & 74.7 & 26.2 & - \\
\hline & $1,2,3,4,7,8,9-\mathrm{HpCDF}$ & & 96.5 & 90.3 & 6.6 & - \\
\hline & OCDF & & 67.5 & 66.8 & 1.0 & - \\
\hline
\end{tabular}

\section{Dangerous Waste Characteristics}

Analyses performed to examine the dangerous waste characteristics followed EPA SW-846 methods indicated in Tables 3.1 and 3.2 except where noted in this subsection. For the ignitability test, the SOP was modified to allow for use of a one-gram sample in a four-inch strip instead of a 250x20x10-millimeter strip. Laboratory control and matrix spike samples are not applicable to the ignitability tests. Recoveries, precision, and calibration check sample results for the other analyses have been included in Tables 4.1 and 4.2. 
WSRC-TR-2001-00109, Revision 1

SRT-RPP-2001-00026, Revision 1

Formerly BNF-003-98-0252

Table 4.2. Summary of QA Results for Toxicity Characteristic Leaching Procedure

\begin{tabular}{|c|c|c|c|c|c|}
\hline Analyte & \multicolumn{4}{|c|}{ Recovery (\%) } & Calibration (\%) \\
\hline & LCS & MS & MSD & Relative Deviation & \\
\hline Sb & 103 & 104 & 111 & 6.1 & 103-107 \\
\hline As & 107 & 102.5 & 101 & 1.4 & $102-107$ \\
\hline $\mathbf{B a}$ & 97.9 & - & - & - & $96.5-99.1$ \\
\hline $\mathbf{B e}$ & 99.2 & 100 & 101 & 1.2 & $98.8-101$ \\
\hline Cd & 100 & 92.4 & 93.8 & 1.5 & $98.5-102$ \\
\hline $\mathrm{Cr}$ & 105 & 96.1 & 97.0 & 1.0 & $103-105$ \\
\hline $\mathbf{P b}$ & 98.9 & 90.6 & 94.0 & 3.6 & $99.3-102$ \\
\hline Se & 102 & 91.4 & 99.0 & 8.0 & $100-105$ \\
\hline $\mathbf{A g}$ & 94.2 & 74.4 & 76.8 & 3.2 & $96.8-101$ \\
\hline $\mathrm{Ni}$ & 103 & 95.0 & 97.5 & 2.5 & $102-104$ \\
\hline Tl & 99.0 & 94.4 & 101.5 & 7.3 & $103-108$ \\
\hline $\mathbf{H g}$ & 106 & 26.0 & 26.6 & 2.3 & $95.0-101$ \\
\hline
\end{tabular}

Except for silver and OCDD, recoveries given in Table 4.1 were within the required range (75 to 125 percent for metals and 50 to 130 percent for dioxins and furans). Except for 1,2,3,4,6,7,8$\mathrm{HpCDF}$, all relative deviations were acceptable (below 20 percent for metals and 25 percent for dioxins and furans). In addition, although arsenic analyses met all other specifications, interference check samples indicated that interference may have caused reported arsenic results to be higher than actual concentrations.

Silver recoveries were thought to have been low because of the formation and precipitation of silver chloride in the acid-dissolved glass samples. Glass samples dissolved using the sodium peroxide fusion method were expected to be free of such interferences. No recovery analysis was performed on the peroxide fusion samples. Results from analysis of the peroxide fusion samples have been included in Chapter 5.0 Results with the appropriate qualifications.

The OCDD detection limit was set by application of the CLP 5x rule to the method blank analysis. Analytical results below these detection limits have been included in Chapter 5.0 Results with the appropriate qualifications. For the other analytes given in Table 4.1, detection limits were those determined by the laboratories according to SW-846 calibration protocol. 


\section{WSRC-TR-2001-00109, Revision 1 \\ SRT-RPP-2001-00026, Revision 1 \\ Formerly BNF-003-98-0252}

Dioxin and furan contamination was evident. Because of this, OCDD recoveries could not be determined. In addition, OCDD was detected in the method blank. Low concentrations of OCDD in the samples were below the detection limits as defined in the preceding paragraph. OCDF and $1234678 \mathrm{HpCDD}$ were detected in the samples at concentrations greater than the method detection limit. In all cases, the concentration detected in the samples were less than the concentrations in the field and process blanks.

The TCLP analyses were performed according to EPA SW-846 Method 1311. The SOP was modified to allow for use of a five-gram sample instead of a one-hundred-gram sample. In addition, the matrix spike and matrix spike duplicate were each prepared with 25 milliliters of the TCLP extract while 45 milliliters were used for preparation and analysis of the samples.

Except for barium, mercury, and silver, recoveries given in Table 4.2 were within the required range (75 to 125 percent). Except for barium, all relative deviations were acceptable (below 20 percent). In addition, although arsenic analyses met all other specifications, interference check samples indicated that interference might have caused reported arsenic results to be higher than actual concentrations. Arsenic results are reported in Chapter 5.0 Results with the appropriate note.

Although barium, mercury, and silver recoveries were outside of the acceptable range, recoveries for the total metals analyses (Table 4.1) were acceptable for barium and mercury. Therefore, these analyses will be used in Chapter 5.0 Results to draw conclusions regarding TCLP results for these metals. A similar case will be made for silver. For silver, recoveries for the aciddissolved samples were not acceptable.

Detection limits for mercury, antimony, cadmium, chromium, and lead were based on application of the EPA MDL formula to results from the initial calibration blanks. Analytical results below these detection limits have been included in Chapter 5.0 with the appropriate qualifications. For the other analytes given in Table 4.2, detection limits were those determined by the laboratory according to SW-846 calibration protocol.

\section{B. Analysis to Support Characterization of Glass Waste Form Samples}

The second analyses to be discussed in Chapter 5.0 Results will be analyses that were performed for characterization of the waste. Metals analyses were performed using EPA SW846 Method 3015 followed by Method 6010B. Anion analyses were performed using EPA SW846 Method 9056. Ammonia analyses were performed using EPA Method 350.3. For the ammonia analyses, the SOP was written to allow for a smaller sample size. For the halide analyses, EPA SW-846 Method 9020B was used. 


\section{WSRC-TR-2001-00109, Revision 1 \\ SRT-RPP-2001-00026, Revision 1 \\ Formerly BNF-003-98-0252}

Most recoveries given in Table 4.3 were within the required range (75 to 125 percent). Recoveries that were outside of the required range fell into one of three cases. First, in some cases, recoveries were outside of the specified range because of limitations in the preparation or analytical methods. In other cases, recoveries were outside of the specified range because samples were spiked with analyte concentrations well below the sample concentration. In still other cases, recoveries were not measured.

The bismuth matrix spike and duplicate recoveries were both below the required range. In addition, the matrix spike recovery precision was slightly outside of the required range. Bismuth recoveries were low. This was hypothesized to be due to an interference. One of the uranium matrix spikes was also slightly outside of the required range. No explanation has been given for this result. The corresponding sample results have been included in Chapter 5.0 Results along with an appropriate note.

For several of the analytes, reported recoveries were outside of the acceptable range not so much because of problems with the preparation or analytical methods, but because the amount of the analyte used was too low. For thallium, one of the LCSs was less than five times the detection limit. The error associated with this analysis, therefore caused the recovery to be outside of the specified range. For other analyte recoveries, the amount spiked into the sample was much less than the amount already in the sample. The result from analysis of these matrix spikes were very close to the expected analytical value, but because of the error associated with taking the difference of two large numbers, the recoveries were outside of the specified range. This was the case for the following:

$\begin{array}{lllll}\text { Aluminum } & \text { Calcium } & \text { Iron } & \text { Magnesium } & \text { Sodium }\end{array}$

Laboratory control samples were not available for all of the analytes. In addition, matrix spike and matrix spike duplicates were not prepared for all of the analytes. Results for these analytes have been included in Chapter 5.0 Results along with a note explaining which of the spikes was not completed. The following results do not have one of the corresponding spike samples:

$\begin{array}{llllll}\text { No LCS: } & \begin{array}{l}\text { Calcium } \\ \text { Palladium }\end{array} & \begin{array}{l}\text { Potassium } \\ \text { Silicon }\end{array} & \begin{array}{l}\text { Magnesium } \\ \text { Tin }\end{array} & \begin{array}{l}\text { Sodium } \\ \text { Anions }\end{array} & \begin{array}{l}\text { Platinum } \\ \text { Halides }\end{array} \\ \text { No MS or MSD: } & \text { Boron } & \text { Palladium } & \text { Platinum } & \text { Silicon } & \text { Tin }\end{array}$

One of four interference check samples for beryllium and two of four interference check samples for thallium were slightly low (76 to 77 percent). The other interference check samples for these analytes were above 80 percent. In addition, the detection limit for antimony was based on application of the EPA MDL formula to the calibration blank results. The results for beryllium and thallium and antimony have been included in Chapter 5.0 Results with the appropriate qualification. 
WSRC-TR-2001-00109, Revision 1

SRT-RPP-2001-00026, Revision 1

Formerly BNF-003-98-0252

Table 4.3. Summary of QA Results for Characterizing the Envelope A Waste Form

\begin{tabular}{|c|c|c|c|c|c|c|}
\hline \multirow[t]{3}{*}{ Analyte } & \multicolumn{5}{|c|}{ Recovery (\%) } & \multirow[t]{3}{*}{ Calibration (\%) } \\
\hline & \multicolumn{2}{|c|}{ LCS } & MS & MSD & Relative Deviation & \\
\hline & Acid & Fusion & & & & \\
\hline Al & 98.7 & 100 & 21.0 & 18.0 & 0.2 & $96.8-98.6$ \\
\hline $\mathbf{B}$ & 96.8 & - & - & - & - & $94.5-98.1$ \\
\hline $\mathbf{B e}$ & 95.1 & 96.2 & 94.3 & 95.8 & 1.5 & $99.3-102$ \\
\hline $\mathbf{B i}$ & 91.5 & - & 38.2 & 38.8 & 1.6 & $97.7-98.2$ \\
\hline $\mathbf{C a}$ & - & - & 63.8 & 66.3 & 0.3 & $102-109$ \\
\hline Co & 97.0 & 98.5 & 96.2 & 97.5 & 1.4 & $102-103$ \\
\hline $\mathbf{C u}$ & 89.7 & 99.4 & 93.9 & 94.5 & 0.4 & $99.2-101$ \\
\hline $\mathbf{F e}$ & 95.9 & 98.3 & - & - & 0.1 & 98.6-103 \\
\hline $\mathbf{K}$ & - & - & 93.1 & 93.7 & 0.5 & $99.1-100.5$ \\
\hline $\mathbf{L i}$ & 98.3 & - & 99.3 & 100 & 1.0 & 101-102 \\
\hline $\mathbf{M g}$ & - & - & 64.4 & 65.7 & 0.2 & $96.2-98.4$ \\
\hline Mn & 94.0 & 95.3 & 93.5 & 94.7 & 1.3 & 99.1-101 \\
\hline Mo & 96.2 & - & 95.8 & 94.5 & 1.4 & 99.1-101 \\
\hline $\mathbf{N a}$ & - & - & - & - & 0.4 & 101-105 \\
\hline $\mathbf{P}$ & 96.0 & - & 95.1 & 96.3 & 1.1 & $91.3-96.0$ \\
\hline $\mathbf{P t}$ & - & - & - & - & - & $97.2-102$ \\
\hline Pd & - & - & - & - & - & $100-108$ \\
\hline $\mathbf{R h}$ & 98.5 & - & 93.7 & 93.7 & 0.1 & $95.8-100.5$ \\
\hline $\mathbf{S}$ & 85.0 & - & 84.1 & 82.7 & 1.4 & $93.3-96.2$ \\
\hline $\mathrm{Sb}$ & 101 & 97.6 & 99.6 & 101 & 1.1 & 99.9-103 \\
\hline $\mathbf{S i}$ & - & - & - & - & - & 99.4-104 \\
\hline Sn & - & - & - & - & - & $98.2-104$ \\
\hline $\mathbf{T a}$ & 80.5 & - & 87.8 & 80.4 & 7.6 & $95.9-97.1$ \\
\hline $\mathbf{T l}$ & 85.7 & 141 & 103 & 101 & 1.6 & $100-108$ \\
\hline $\mathbf{U}$ & - & - & 73.0 & 78.1 & 6.7 & $94.5-94.8$ \\
\hline $\mathbf{V}$ & 95.5 & 95.7 & 94.5 & 95.0 & 0.5 & $99.2-101$ \\
\hline $\mathbf{W}$ & 87.0 & - & 91.4 & 85.4 & 6.5 & $101.5-106$ \\
\hline $\mathbf{Y}$ & 98.8 & - & 102 & 99.6 & 2.2 & 99.6-102.5 \\
\hline Zn & 96.1 & 97.3 & 36.0 & 36.0 & 0.0 & $101-105$ \\
\hline $\mathbf{Z r}$ & 105 & - & 77.0 & 81.0 & 0.6 & $102-103$ \\
\hline $\mathrm{Br}$ & - & - & - & - & - & 106-109 \\
\hline Cl & - & - & - & - & - & $90.6-93.8$ \\
\hline $\mathbf{F}$ & - & - & - & - & - & $94.0-101$ \\
\hline $\mathrm{NO}_{3}$ & - & - & - & - & - & 95.8-104 \\
\hline $\mathrm{NO}_{2}$ & - & - & - & - & - & 97.6-100 \\
\hline $\mathrm{PO}_{4}$ & - & - & - & - & - & $99.2-102$ \\
\hline $\mathrm{SO}_{4}$ & - & - & - & - & - & 99.6-100 \\
\hline $\mathbf{N H}_{3}$ & 102 & 108 & 100 & 97.1 & 3.1 & 94-105 \\
\hline Halide & 103 & 101 & - & - & - & - \\
\hline
\end{tabular}




\section{WSRC-TR-2001-00109, Revision 1 \\ SRT-RPP-2001-00026, Revision 1 \\ Formerly BNF-003-98-0252}

Matrix effects caused a baseline shift during the initial phase of the ion chromatography analyses. Because of these matrix effects, chloride and fluoride could not be determined in these samples. In addition, although analysis indicated that nitrate was in the samples, these matrix effects made quantitation impossible. To quantitate nitrate, phosphate and sulfate, the procedure was modified to initiate peak integration after the nitrite peak elution.

Detection limits for ammonia were based on application of the $5 x$ rule to results from the trip blank supplied with the samples. No method blank was run with these samples. In addition, the laboratory determined halide detection limits from the blank responses and the amount of sample used. A detection limit study had not been completed on this method.

\section{Analysis to Support Permitting}

The third analyses to be discussed in Chapter 5.0 Results will be those performed to support permitting. Volatile organic analytes were determined by EPA SW-846 Method 8260, 9056 (modified as discussed in Chapter 3.0 Experimental), or 8015. Although triethylamine (TEA) is usually considered to be semivolatile, TEA results were included with the volatile organic compounds because it was also determined by IC. Semivolatile organic analytes, pesticides, and PCBs were determined by EPA SW-846 Methods 8270, 8081, and 8082 respectively.

\section{Volatile Organic Compounds}

With the exceptions noted in this subsection, all volatile organic compound analyses met the specifications of Reference 2, Reference 3 and EPA SW-846. In all cases, analyses were performed within the hold times indicated. Blanks included field blanks and trip blanks. Results from analyses of these blanks are in included in Chapter 5.0 Results. Unless otherwise indicated, laboratory method blanks were free of volatile organic compounds.

a. Volatile Organic Compounds Measured Using EPA SW-846 Method 8260

With the exceptions noted below, results from the EPA SW-846 Method 8260 analyses met all applicable quality assurance requirements. These requirements included a bromofluorobenzene tune of the analytical instrumentation, calibration requirements, and recovery requirements. Results from the matrix spike and matrix spike duplicate have been given in Table 4.4 along with some of the laboratory control sample results. 
WSRC-TR-2001-00109, Revision 1

SRT-RPP-2001-00026, Revision 1

Formerly BNF-003-98-0252

Table 4.4. Summary of QA Results for Compounds Determined by Method 8260B

\begin{tabular}{|c|c|c|c|c|}
\hline Analyte & LCS & MS & MSD & Relative Deviation \\
\hline \hline 1,1-Dichloroethene & 120 & 208 & 184 & 12 \\
\hline Benzene & 104 & 120 & 124 & 3 \\
\hline Trichloroethene & 100 & 84 & 88 & 5 \\
\hline Toluene & 96 & 130 & 146 & 10 \\
\hline Chlorobenzene & 88 & 96 & 112 & 15 \\
\hline
\end{tabular}

All matrix spike results were within the required range of 50 to 130 percent except for the 1,1dichloroethene values. The 1,1-dichloroethene matrix spike could not be retested because no additional sample was available. The affected sample results have been noted in Chapter 5.0 Results. All relative deviations were within the required range (less than 25 percent). In addition, laboratory control samples were run for several other analytes. Recoveries were between 78 and 128 percent for all laboratory control samples.

Of the three compounds used as internal standards, only 1,2-dichloroethane-d4, recoveries were outside of the 50 to 130 percent range. The corresponding results for acetone and 2-methyl-2propanol have been noted in Chapter 5.0 Results. Other results are not thought to have been affected by the high recoveries since the reported values were below the method detection limits.

Octamethyl cyclotetrasiloxane was reported in the method blank. This compound was also reported to be in one of the samples. Although this compound was not one of the target compounds, it was reported as a tentatively-identified compound. Therefore, this compound was not included in the method calibration. The sample result has been reported in Chapter 5.0 Results along with the appropriate qualification.

Most compounds met calibration linearity requirements (less than fifteen-percent deviation during initial calibration and less than 30 percent during continuing calibration). Those compounds that did not meet the linearity requirements were known to have poor purging characteristics. Of the compounds that did not meet the linearity requirements, only acetone and 2-methyl-2-propanol were reported above the detection limits. These values have been included in Chapter 5.0 Results with an appropriate qualification.

b. Volatile Organic Compounds Measured Using Ion Chromatography

Results from the EPA SW-846 Method 9056 and triethylamine analyses met all applicable quality assurance requirements. These requirements included calibration specifications, recoveries, and blank analyses. No laboratory control samples are required by these methods. Results from the matrix spike and matrix spike duplicate have been given in Table 4.5. All matrix spike results were within the specified ranges (recoveries between 50 and 130 percent and relative deviations less than 25 percent). 
WSRC-TR-2001-00109, Revision 1

SRT-RPP-2001-00026, Revision 1

Formerly BNF-003-98-0252

Table 4.5. Summary of QA Results for Organic Compounds Determined by IC

\begin{tabular}{|c||c|c|c|}
\hline Analyte & MS & MSD & Relative Deviation \\
\hline \hline Formate & 102 & 103 & 0.98 \\
\hline Acetate & 99.1 & 102 & 2.9 \\
\hline Triethylamine & 85.9 & 88.5 & 3.0 \\
\hline
\end{tabular}

Procedures used to prepare these samples and analyze for these analytes have been described in previous chapters. As indicated, the formate and acetate analyses were performed using a EPA SW846 Method 9056 procedure that was modified to allow for separation of formate and acetate. Ion chromatography (IC) was used for triethylamine determination because this analyte cannot be determined by EPA SW846 Method 8260B. Both of the IC methods required calibration verification during sample analysis.

The procedure requires an initial calibration verification prior to sample analyses. The standards used to perform the initial calibration were to be the same as the standards used to make the matrix spike and duplicate. The initial acetate calibration verification showed this standard to be $831 \mathrm{ppm}$ rather than $1000 \mathrm{ppm}$. Another standard was prepared and used for the initial calibration and continuing calibrations. Acetate matrix spike and duplicates were determined using a value of $831 \mathrm{ppm}$.

Initial and continuing calibration verifications for formate and acetate were within ten percent of the known standard concentration. The initial calibration verification for formate was 99.2 percent and the two continuing calibration verifications were 103 and 106 percent. For acetate the initial calibration verification was 97.9 percent and the continuing verifications were 108 and 110 percent.

Although triethylamine was determined by an ion chromatography technique that is not an EPA SW-846 method, the same quality assurance requirements were applied to these analyses as those required by EPA SW-846 Method 9056. Initial and continuing calibration verifications for triethylamine were within ten percent of the known standard concentration. The initial calibration verification for triethylamine was 99.4 percent, and the continuing calibration verifications were 97.2 and 90.5 percent.

\section{c. Methanol}

With the exceptions noted below, results from the EPA SW-846 Method 8015 analyses met all applicable quality assurance requirements. These requirements included calibration specifications, recoveries and blank analyses. No laboratory control samples were used during these analyses. Although EPA SW-846 Method 8015 does indicate that such a spike should be included, the sample used for continuing verification can be used to verify the ability of the analytical technique to measure methanol in aqueous media. 
The matrix spike and duplicate recoveries were 106 and 135 percent. The relative deviation was 21.5 percent. The relative deviation was within the required range (less than 25 percent). The matrix spike was within the required recovery range (between 50 and 130 percent), but the duplicate was not. The analytical laboratory performing the analyses has found 65 to 135 percent to be more appropriate. Although this does not meet specification of Reference 2, it is consistent with EPA SW-846 Method 8000.

EPA SW-846 Method 8015 requires calibration verification to be within 15 percent of the initial calibration. This criterion was met by all initial and continuing calibration verifications. The initial calibration verification was 13.9 percent. The two continuing verifications were 12.9 and 11.0 percent. As noted previously, the continuing calibration verification also acted as a laboratory control sample (used to verify quality of the analytical technique on a sample with a "clean" matrix).

The laboratory noted evidence that one of the field blanks had been compromised. No methanol was found in the field blank. Because neither of the analytical samples was found to have methanol concentrations above the laboratory detection limits, the compromised field blank did not affect the sample results. The result for this field blank has been included in Chapter 5.0 Results along with the appropriate qualification.

\section{Semivolatile Organic Compounds}

With the exceptions noted in this subsection, semivolatile organic compound analyses met specifications of Reference 2, Reference 3, and EPA SW-846. All analyses were performed within the specified hold times. Field blank results have been included in Chapter 5.0 Results. Unless otherwise indicated, laboratory method blanks were found to be free of semivolatile organic compounds. Results from the matrix spike and matrix spike duplicate and from some of the laboratory control sample results have been given in Table 4.6.

Table 4.6. Summary of QA Results for Semivolatile Organic Compounds Analyses

\begin{tabular}{|c|c|c|c|c|}
\hline Analyte & LCS & MS & MSD & Relative Deviation \\
\hline Phenol & 60 & 67 & 57 & 16 \\
\hline 1,4-Dichlorobenzene & 59 & 68 & 62 & 9 \\
\hline 1,2,4-Trichlorobenzene & 65 & 73 & 68 & 7 \\
\hline 2,4-Dinitrotoluene & 59 & 70 & 59 & 17 \\
\hline Pentachlorophenol & 52 & 29 & 25 & 15 \\
\hline
\end{tabular}

All relative deviations were within the range specified for these analyses (less than 25 percent). With the exception of pentachlorophenol, the recoveries were also within the range specified in Reference 2 (between 50 and 130 percent). The range of acceptable recoveries had been changed to between 20 and 130 percent because of experience with these types of compounds. This change was agreed upon prior to initiation of the study and was documented in Reference 3. 
Two tentatively identified compounds (TICs) were reported in all samples and blanks, including the laboratory method blanks. The presence of these compounds in the samples cannot therefore be determined. In fact, by application of the CLP 5x rule to the method blank results, only one of the TICs would be considered detectable. Other TICs were identified in the samples. These are discussed in Chapter 5.0 Results.

Initial and continuing calibrations were all within specifications. Surrogate recoveries were low for several compounds. This appears to be due to the high $\mathrm{pH}$ of the samples. Compounds that were not recovered would not be expected to be compatible with an alkaline matrix. These compounds would therefore not be expected to be present in the samples.

\section{Pesticides}

With the exceptions noted in this subsection, pesticide analyses met specifications of Reference 2, Reference 3, and EPA SW-846. All analyses were performed within the specified hold times. Field blank results have been included in Chapter 5.0 Results. Unless otherwise indicated laboratory method blanks were found to be free of pesticides. Results form the matrix spike and matrix spike duplicate and from the laboratory control sample have been given in Table 4.7.

Table 4.7. Summary of QA Results for Pesticide Analyses

\begin{tabular}{|c|c|c|c|c|}
\hline Analyte & LCS & MS & MSD & Relative Deviation \\
\hline \hline Aldrin & 104 & 73 & 80 & 9 \\
\hline Gamma-BHC (Lindane) & 69 & 47 & 50 & 6 \\
\hline 4,4'-DDT & 94 & 80 & 80 & 0 \\
\hline Dieldrin & 106 & 80 & 80 & 0 \\
\hline Endrin & 141 & 113 & 107 & 5 \\
\hline Heptachlor & 116 & 80 & 84 & 5 \\
\hline
\end{tabular}

All matrix spike and matrix spike duplicate recoveries and all relative deviations were within the specifications given. One of the laboratory control sample compounds, Endrin, was outside of the range that was established for the matrix spike and matrix spike duplicate recoveries. This laboratory control sample result was slightly higher than the allowable matrix spike recovery range (50 to 130 percent).

During the analyses, eleven continuing calibration validations were performed. During one of these, one of the compounds was slightly out of specification. Laboratory experience showed that measured concentrations should be within $15 \%$ of the actual value. During the final continuing calibration validations delta BHC had a deviation of $15.1 \%$. 


\section{WSRC-TR-2001-00109, Revision 1 \\ SRT-RPP-2001-00026, Revision 1 \\ Formerly BNF-003-98-0252}

\section{Polychlorinated Biphenyls}

Polychlorinated biphenyl (PCB) analyses met specifications of Reference 2, Reference 3, and EPA SW-846. All analyses were performed within the specified hold times. Field blank results have been included in Chapter 5.0 Results. Laboratory method blanks were found to be free of pesticides. Results form the matrix spike and matrix spike duplicate and from the laboratory control sample have been given in Table 4.8.

Table 4.8. Summary of QA Results for Polychlorinated Biphenyl Analyses

\begin{tabular}{|c||c|c|c|c|}
\hline Analyte & LCS & MS & MSD & Relative Deviation \\
\hline \hline Aroclor-1016 & 88 & 80 & 73 & 9 \\
\hline Aroclor-1260 & 82 & 87 & 87 & 0 \\
\hline
\end{tabular}

\section{Radionuclides}

With the exception of the gross alpha and gross beta analyses, the methods used to determine the radionuclide content of the glass were not EPA SW-846 methods. Whenever applicable EPA SW-846 protocol was applied to these analyses. For example, use of laboratory control samples and application of initial and continuing calibrations were applied to these samples. Recovery results for the laboratory control samples have been given in Table 4.9.

Carbon-14 was reported to be detected in fifteen of twenty samples, standards and blanks that were analyzed. The carbon-14 method used is susceptible to interference from cesium-137, technetium-99, and radon. During validation of the data, the carbon-14 analyses were found to be greatly influenced by the presence of cesium-137 and naturally-occurring radon. In addition, application of the $5 \mathrm{x}$ rule to the tritium and iodine-129 method blank results showed the reported sample concentrations to be "nondetects".

Plutonium-241, carbon-14 and gross alpha recoveries were slightly outside of the range specified in the project QAPjP (70 to $125 \%$ ). ${ }^{2}$ Selenium-79 was also determined for these samples. Because a standard was not available, laboratory control standard recovery could not be determined. Recovery of this radionuclide is known to be poor. These determinations were not different. Recoveries were determined to be as low as 12 percent. This is similar to recoveries seen at the Savannah River Technology Center. Although neptunium-237 was reported in one of the samples, validation showed no peak to be present. The result has been noted with the appropriate indicator. 
Table 4.9. Summary of LCS Recoveries for Radionuclide Analyses

\begin{tabular}{|c|c|}
\hline Analyte & LCS Recovery (\%) \\
\hline U-234 & 113 \\
\hline U-235 & 95 \\
\hline U-238 & 117 \\
\hline Pu-239/240 & 116 \\
\hline Pu-241 & 115 \\
\hline Am-241 & 74 \\
\hline I-129 & 112 \\
\hline H-3 & 91 \\
\hline C-14 & 69 \\
\hline Sr-90 & 108 \\
\hline Tc-99 & 95 \\
\hline Gross Alpha & 131 \\
\hline Gross Beta & 111 \\
\hline
\end{tabular}

\subsection{Results}

Results from the sample analyses are presented in this chapter. In most cases, these results are presented in the same order as the analytes listed in Tables 1 through 5 of Reference 1. In addition to the sample results, values for the field blanks and process blanks have been included in some cases. A nine-volume data package will be issued that will include all results from the samples, process blanks, field blanks, and standards.

The title of each section in this chapter was taken from the corresponding table in Reference 1. Titles are not meant to suggest that the designated activities are underway. For example, Section A is titled "Analysis to Support Delisting Petition." At this time, the authors are not involved in efforts toward delisting the low-activity waste forms from the Hanford High-Level Waste tanks.

The $\mathrm{QAPj} \mathrm{P}^{2}$ listed five types of quality control samples. One of these, equipment rinsate blanks, were not applicable to these analyses because sample collection was performed by transferring material from one container to the sample containers without the use of sampling equipment. The following quality control samples were submitted with these samples:

-Trip blanks were submitted with each set of samples that were analyzed for volatile organic compounds.

-Duplicate samples were submitted for all analyses except TCLP.

-Method blanks were prepared and analyzed by the subcontractor for all analyses except physical properties and ammonia determinations.

-Matrix spike and matrix spike duplicates were prepared for all analyses except physical properties and most radionuclide determinations. Recoveries (analyte measured/analyte in 


\section{WSRC-TR-2001-00109, Revision 1 \\ SRT-RPP-2001-00026, Revision 1 \\ Formerly BNF-003-98-0252}

samples) were within the ranges indicated in the QAPjP unless otherwise indicated in this report.

In this report, estimated quantitation limits (EQLs) are reported as ten times the method detection limits (MDLs). EQLs are normally defined as five or ten times the MDL with some laboratories using as low as three times the MDL. EPA SW-846 states in Chapter One, Section 5.0, "The EQL is generally 5 to 10 times the MDL." This is repeated in several SW-846 methods including Methods $8260 \mathrm{~B}$ and $8270 \mathrm{C}$. For this report, the EQL was conservatively assumed to be 10 times the MDL.

\section{A. Analysis to Support Delisting Petition}

Results presented in this section are those specified in Table 1 of Reference 1. While some of the TCLP results were higher than expected (e.g. barium results), all results showed that the glass waste form did not have any characteristics of dangerous waste. Specifically, the waste form was not ignitable, not reactive and not toxic, and did not contain cyanide concentrations above those specified in the code of federal regulations.

\section{Miscellaneous}

Results for the cyanide analyses were $<0.102 \mathrm{mg} / \mathrm{kg}$ for all samples and blanks. Total oil and grease and sulfide measurements were not made on these samples. This is consistent with the QAPjP, the task plan, and discussions held between RPP personnel and SRTC. Oil and grease would not have survived the vitrification environment $\left(1150{ }^{\circ} \mathrm{C}\right)$. Sulfur in these samples was measured by ICP-ES and as sulfate IC. These results have been included in Section 5.B.

As expected, cyanide was not detected in the samples or in the blanks. Detection limits were limited by the quantity of sample available for the analyses. The quantities were sufficient to show that cyanide concentrations in the glass were less than $0.102 \mathrm{mg} / \mathrm{kg}$. These values are well below the land disposal restriction limits given in 40CFR268 for total cyanide $(590 \mathrm{mg} / \mathrm{kg}$ ) and for amenable cyanide $(30 \mathrm{mg} / \mathrm{kg})$.

\section{Dangerous Waste Characteristics}

Results from the target RCRA metals analyses and target TCLP analytes have been given in Table 5.1 and Table 5.2. The TCLP results for the target analytes were at least an order of magnitude below any of the universal treatment standards except barium. Even barium was less than an eighth of the universal treatment standard. From the results in Table 5.1 for the total metals, only chromium, silver, and nickel would fail TCLP even if all of these species were to leach from the glass waste form. 
WSRC-TR-2001-00109, Revision 1

SRT-RPP-2001-00026, Revision 1

Formerly BNF-003-98-0252

Table 5.1. Analyses to Determine if Samples Have Dangerous Waste Characteristics

\begin{tabular}{|c|c|c|c|c|c|c|c|}
\hline \multirow[t]{2}{*}{ Characteristic } & \multirow[t]{2}{*}{ Analyte } & \multicolumn{4}{|c|}{ Samples } & \multicolumn{2}{|c|}{ Field Blank } \\
\hline & & \multicolumn{2}{|c|}{1} & \multicolumn{2}{|c|}{2} & & \\
\hline Ignitability** & - & \multicolumn{2}{|c|}{ NF } & \multicolumn{2}{|c|}{$\mathrm{NF}$} & \multicolumn{2}{|c|}{$\mathrm{NF}$} \\
\hline & & \multicolumn{2}{|c|}{ Acid } & \multicolumn{2}{|c|}{ Fusion } & Acid & Fusion \\
\hline & & 1 & 2 & 1 & 2 & & \\
\hline \multirow{10}{*}{$\begin{array}{l}\text { Total Metals } \\
\text { (mg/kg) }\end{array}$} & As & ${ }^{++}<2.1 \times 10^{2}$ & ${ }^{++}<2.0 \times 10^{2}$ & ${ }^{++}<3.5 \times 10^{3}$ & ${ }^{++}<3.6 \times 10^{3}$ & $<1.4 \times 10^{2}$ & $<1.6 \times 10^{4}$ \\
\hline & $\mathrm{Ba}$ & 62 & 65 & $<2.0 \times 10^{2}$ & $<2.0 \times 10^{2}$ & $1.1 \times 10^{3}$ & $<9.0 \times 10^{2}$ \\
\hline & $\mathrm{Cd}$ & $<2.4$ & $<2.4$ & $<2.4 \times 10^{2}$ & $<2.4 \times 10^{2}$ & $<9$ & $<1.1 \times 10^{3}$ \\
\hline & $\mathrm{Cr}$ & $3.0 \times 10^{2}$ & $3.0 \times 10^{2}$ & $<4.9 \times 10^{2}$ & $<5.0 \times 10^{2}$ & ${ }^{+}<23$ & $\left(2.7 \times 10^{3}\right)$ \\
\hline & $\mathrm{Pb}$ & $\begin{array}{l}{ }^{+}<85 \\
\end{array}$ & ${ }^{+}<82$ & $<5.5 \times 10^{3}$ & $<5.5 \times 10^{3}$ & $<2.2 \times 10^{2}$ & $<2.5 \times 10^{4}$ \\
\hline & $\mathrm{Se}$ & $<30$ & $<29$ & $<2.9 \times 10^{3}$ & $<3.0 \times 10^{3}$ & $<1.1 \times 10^{2}$ & $<1.3 \times 10^{4}$ \\
\hline & $\mathrm{Ag}$ & $* 1.1 \times 10^{2}$ & $* 1.1 \times 10^{2}$ & $*<8.1 \times 10^{2}$ & $*<8.3 \times 10^{2}$ & $*<31$ & $*<3.7 \times 10^{3}$ \\
\hline & $\mathrm{Ni}$ & $1.4 \times 10^{2}$ & $\left(1.2 \times 10^{2}\right)$ & - & - & $\left(1.1 \times 10^{2}\right)$ & - \\
\hline & $\mathrm{Hg}$ & $<0.099$ & $<0.098$ & ${ }^{+}<0.088$ & $<0.01$ & ${ }^{+}<0.37$ & $<0.40$ \\
\hline & & \multicolumn{2}{|c|}{1} & \multicolumn{2}{|c|}{2} & \\
\hline Volatiles & - & \multicolumn{2}{|c|}{ Sect. 5.C.1 } & \multicolumn{2}{|c|}{ Sect. 5.C.1 } & \multicolumn{2}{|c|}{ Sect. 5.C.1 } \\
\hline Semivolatiles & - & \multicolumn{2}{|c|}{ Sect. 5.C. 2} & \multicolumn{2}{|c|}{ Sect. 5.C.2 } & \multicolumn{2}{|c|}{ Sect. 5.C.2 } \\
\hline & $2,3,7,8,-$ TCDD & \multicolumn{2}{|c|}{$<0.0369$} & \multicolumn{2}{|c|}{$<0.0621$} & \multicolumn{2}{|c|}{$<0.100$} \\
\hline & $1,2,3,7,8-\mathrm{PeCDD}$ & \multicolumn{2}{|c|}{$<0.283$} & \multicolumn{2}{|c|}{$<0.188$} & \multicolumn{2}{|c|}{$<0.309$} \\
\hline & $1,2,3,4,7,8-\mathrm{HxCDD}$ & & & $<0$. & 330 & & \\
\hline & $1,2,3,6,7,8-\mathrm{HxCDD}$ & & & & & & \\
\hline & $1,2,3,7,8,9-\mathrm{HxCDD}$ & & & & & & \\
\hline & $1,2,3,4,6,7,8-\mathrm{HpCDD}$ & & & & & & \\
\hline & OCDD $* * * *$ & & & & & & \\
\hline & $2,3,7,8-\mathrm{TCDF}$ & & & $<0$. & 913 & & \\
\hline $\begin{array}{l}\text { Dioxins \& Furans } \\
(\mathrm{ng} / \mathrm{q})\end{array}$ & $1,2,3,7,8-\mathrm{PeCDF}$ & & & & & & $35)$ \\
\hline & $2,3,4,7,8-\mathrm{PeCDF}$ & $<0$. & 85 & $<0$. & 660 & & 434 \\
\hline & $1,2,3,4,7,8-\mathrm{HxCDF}$ & & & & & & \\
\hline & $1,2,3,6,7,8-\mathrm{HxCDF}$ & & & & & & 19 \\
\hline & $1,2,3,7,8,9-\mathrm{HxCDF}$ & $<0$. & 30 & $<0$. & 194 & & 302 \\
\hline & $2,3,4,6,7,8-\mathrm{HxCDF}$ & $<0$. & 60 & $<0$. & 374 & & 368 \\
\hline & $1,2,3,4,6,7,8-\mathrm{HpCDF}$ & & & & & & \\
\hline & $1,2,3,4,7,8,9-\mathrm{HpCDF}$ & & & & & & \\
\hline & OCDF & & & & & & \\
\hline
\end{tabular}

() Parentheses indicate analytes that were detected but at concentrations less than 10x the method detection limit.

*Silver recoveries were very low on acid dissolutions. Although this was not expected to have been the case with the peroxide fusions, separate matrix spikes and matrix spike duplicates were not analyzed for the peroxide fusion samples.

**Recoveries were not within the specified range of between 50 and $130 \%$ on the matrix spikes or matrix spike duplicates for these analytes.

***N F indicates a "not flammable" result in the ignitability test (Method 1030 modified for smaller sample size).

****These results are to be interpreted as nondetects based on application of the $5 \mathrm{X}$ rule to the method blank.

${ }^{+}$These results are to be interpreted as nondetects based on application of the EPA's MDL formula using calibration blank results.

${ }^{++}$These results are to be interpreted as nondetects based on interference check samples.

Results from analysis of the TCLP leachate analysis indicated that the method detection limit was too high for thallium to determine whether the thallium leachate concentration would have been below the UTS limit. Although not included as one of the TCLP target analytes, the thallium method detection limits have been included along with the other TCLP results in Table 5.2.

Table 5.2. Results from TCLP, Toxicity Characteristic Leaching Procedure 
WSRC-TR-2001-00109, Revision 1

SRT-RPP-2001-00026, Revision 1

Formerly BNF-003-98-0252

\begin{tabular}{|c||c|c|c|c|}
\hline & \multicolumn{2}{|c|}{ TCLP Limit $(\mu \mathbf{g} / \mathbf{L})$} & Sample $(\mu \mathbf{g} / \mathbf{L})$ & Field Blank $(\mu \mathbf{g} / \mathbf{L})$ \\
\hline & UTS & Characteristically Hazardous & & \\
\hline & & & & \\
\hline Sb & 1150 & - & $<21.4$ & $<21.4$ \\
\hline $\mathbf{A s}$ & 5000 & 5000 & $<20.0$ & $<20.0$ \\
\hline $\mathbf{B a}$ & 21000 & 100000 & $* 2460$ & $* 2150$ \\
\hline $\mathbf{B e}$ & 1220 & - & $* *<0.889$ & $* *<0.667$ \\
\hline $\mathbf{C d}$ & 110 & 1000 & $<1.33$ & $<1.33$ \\
\hline $\mathbf{C r}$ & 600 & 5000 & $(8.44)$ & $<3.22$ \\
\hline $\mathbf{P b}$ & 750 & 5000 & $<33.0$ & $(45.3)$ \\
\hline $\mathbf{S e}$ & 5700 & 1000 & $<16.6$ & $<16.6$ \\
\hline $\mathbf{A g}$ & 140 & 5000 & $*<4.59$ & $*(22.9)$ \\
\hline $\mathbf{N i}$ & 11000 & - & $(9.44)$ & $(8.44)$ \\
\hline $\mathbf{T l}$ & 200 & - & $<67.6$ & $<67.6$ \\
\hline $\mathbf{H g}$ & 25 & 200 & $*<0.50$ & $*<0.50$ \\
\hline
\end{tabular}

() Parentheses indicate analytes detected but at concentrations less than 10x the method detection limit.

*Recoveries were not within the specified range of between 75 and $125 \%$ (for metal analyses) on the matrix spikes or matrix spike duplicates for these analytes.

**Results considered nondetects based on measured concentrations in extraction blanks.

Recovery of barium and mercury in TCLP leachates was problematic; however glass concentrations of these metals were so low that they would pass TCLP even if they leached completely. Recovery of silver was slightly low (74.4\%) for the matrix spike. Results given in Table 5.1 show that one of the field blanks appears to have been contaminated with barium and a small amount of nickel.

Process blank TCLP results were below the method detection limits for all RCRA metals except barium $(2280 \mu \mathrm{g} / \mathrm{L})$, mercury, beryllium, cadmium, and chromium. Results for mercury $(0.07$ $\mu \mathrm{g} / \mathrm{L})$, beryllium $(0.444 \mu \mathrm{g} / \mathrm{L})$, cadmium $(1.56 \mu \mathrm{g} / \mathrm{L})$, and chromium $(7.89 \mu \mathrm{g} / \mathrm{L})$ were very close to the detection limits. Detection limits were $1 \mu \mathrm{g} / \mathrm{L}$ for barium and cadmium, $0.2 \mu \mathrm{g} / \mathrm{L}$ for beryllium, $3 \mu \mathrm{g} / \mathrm{L}$ for chromium, and $0.05 \mu \mathrm{g} / \mathrm{L}$ for mercury.

\section{B. Analysis to Support Characterization of Envelope A Waste Form Samples}

Results from elemental and anion analyses have been presented in Table 5.3. The "Acid" heading in Table 5.3 refers to analysis of duplicate samples dissolved by the acid dissolution. The "Fusion" heading in Table 5.3 refers to analysis of duplicate samples dissolved by the peroxide fusion dissolution. The four columns under the "Sample" heading are therefore quadruplicate analyses. Each of these columns should have been compared to the composition that was targeted in the vitrification demonstration. 
WSRC-TR-2001-00109, Revision 1

SRT-RPP-2001-00026, Revision 1

Formerly BNF-003-98-0252

Table 5.3. Results (mg/kg) in Support of Characterizing Envelope A Glass Waste Form Samples

\begin{tabular}{|c|c|c|c|c|c|c|c|}
\hline \multirow[b]{3}{*}{ Al } & \multicolumn{5}{|c|}{ Sample } & \multicolumn{2}{|c|}{ Field Blank } \\
\hline & \multicolumn{2}{|c|}{ Acid } & \multicolumn{2}{|c|}{ Fusion } & \multirow{2}{*}{$\begin{array}{c}\text { Target } \\
3.3 \times 10^{4}\end{array}$} & \multirow{2}{*}{$\begin{array}{c}\text { Acid } \\
4.7 \times 10^{4}\end{array}$} & \multirow{2}{*}{$\begin{array}{c}\text { Fusion } \\
\left(6.8 \times 10^{4}\right)\end{array}$} \\
\hline & $3.5 \times 10^{4}$ & $3.5 \times 10^{4}$ & $4.2 \times 10^{4}$ & $3.7 \times 10^{4}$ & & & \\
\hline B & - & - & $2.9 \times 10^{4}$ & $2.6 \times 10^{4}$ & $2.8 \times 10^{4}$ & - & $<4400$ \\
\hline $\mathbf{B e}$ & $<0.46$ & $<0.45$ & $<45$ & $<46$ & ND & $(2.3)$ & $<2.1 \times 10^{2}$ \\
\hline $\mathbf{B i}$ & $*<97$ & $*<96$ & $*<96$ & $*<98$ & ND & $*<370$ & $*<440$ \\
\hline $\mathbf{C a}$ & $1.5 \times 10^{4}$ & $1.5 \times 10^{4}$ & $\left(1.7 \times 10^{4}\right)$ & $\left(1.6 \times 10^{4}\right)$ & $1.4 \times 10^{4}$ & $4.5 \times 10^{3}$ & $<47000$ \\
\hline Co & $<5.2$ & $(7.1)$ & $<510$ & $<520$ & ND & $<20$ & $\left(2.5 \times 10^{3}\right)$ \\
\hline $\mathbf{C u}$ & $8.3 \times 10^{2}$ & $8.3 \times 10^{2}$ & - & - & 0.89 & $8.2 \times 10^{2}$ & - \\
\hline $\mathbf{F e}$ & $4.7 \times 10^{4}$ & $4.6 \times 10^{4}$ & $\left(5.0 \times 10^{4}\right)$ & $\left(5.0 \times 10^{4}\right)$ & $4.9 \times 10^{4}$ & $5.5 \times 10^{3}$ & $<2600$ \\
\hline $\mathbf{K}$ & $5.5 \times 10^{3}$ & $5.3 \times 10^{3}$ & - & - & $5.6 \times 10^{3}$ & $3.0 \times 10^{4}$ & - \\
\hline $\mathbf{L i}$ & $(12)$ & $<12$ & $<12$ & $<12$ & 1.9 & $<46$ & $<55$ \\
\hline $\mathrm{Mg}$ & $1.2 \times 10^{4}$ & $1.2 \times 10^{4}$ & $\left(1.3 \times 10^{4}\right)$ & $\left(1.0 \times 10^{4}\right)$ & $1.2 \times 10^{4}$ & $\left(1.1 \times 10^{3}\right)$ & $<18000$ \\
\hline Mn & $1.0 \times 10^{2}$ & $1.0 \times 10^{2}$ & - & - & ND & (59) & - \\
\hline Mo & $(33)$ & $<28$ & $<28$ & $<28$ & 53 & $<110$ & $<130$ \\
\hline $\mathbf{N a}$ & $1.4 \times 10^{5}$ & $1.4 \times 10^{5}$ & - & - & $1.5 \times 10^{5}$ & $1.8 \times 10^{4}$ & - \\
\hline $\mathbf{P}$ & $\left(2.3 \times 10^{2}\right)$ & $\left(2.4 \times 10^{2}\right)$ & $\left(2.4 \times 10^{2}\right)$ & $\left(2.6 \times 10^{2}\right)$ & ND & $<750$ & $<890$ \\
\hline $\mathbf{P t}$ & $<56$ & $<55$ & $<55$ & $<56$ & ND & $<210$ & $<250$ \\
\hline Pd & $<24000$ & $<24000$ & $<24000$ & $<24000$ & ND & $<91000$ & $<110000$ \\
\hline $\mathbf{R h}$ & $<970$ & $<960$ & $<960$ & $<970$ & ND & $<3700$ & $<4400$ \\
\hline $\mathbf{S}$ & $6.8 \times 10^{2}$ & $7.0 \times 10^{2}$ & $6.1 \times 10^{2}$ & $5.9 \times 10^{2}$ & ND & $6.7 \times 10^{3}$ & $\left(8.0 \times 10^{2}\right)$ \\
\hline Sb & $<38$ & $<38$ & $<3800$ & $<3900$ & ND & $1.9 \times 10^{2}$ & $<17000$ \\
\hline $\mathbf{S i}$ & $*\left(2.8 \times 10^{5}\right)$ & $*\left(2.1 \times 10^{5}\right)$ & $*\left(1.6 \times 10^{5}\right)$ & $*\left(1.9 \times 10^{5}\right)$ & $2.1 \times 10^{5}$ & $*\left(3.5 \times 10^{5}\right)$ & $*\left(3.8 \times 10^{5}\right)$ \\
\hline Sn & $<84$ & $<84$ & $<84$ & $<85$ & 50 & $<320$ & $<380$ \\
\hline $\mathbf{T a}$ & $\left(5.5 \times 10^{2}\right)$ & $<300$ & $<300$ & $<300$ & ND & $<1200$ & $<1400$ \\
\hline Tl & $<120$ & $<120$ & $<12000$ & $<12000$ & ND & $<460$ & $<55000$ \\
\hline $\mathbf{U}$ & $*<1300$ & $*<1300$ & $*<1300$ & $*<1300$ & ND & $*<5000$ & $*<5900$ \\
\hline $\mathbf{V}$ & $(72)$ & (69) & $<870$ & $<890$ & 0.56 & $<33$ & $<4000$ \\
\hline $\mathbf{W}$ & $\left(1.9 \times 10^{2}\right)$ & $<130$ & $<130$ & $<130$ & ND & $<500$ & $<600$ \\
\hline $\mathbf{Y}$ & (24) & $(25)$ & (22) & (20) & ND & $<60$ & $<72$ \\
\hline $\mathbf{Z n}$ & $2.4 \times 10^{4}$ & $2.3 \times 10^{4}$ & $2.4 \times 10^{4}$ & $2.4 \times 10^{4}$ & $2.4 \times 10^{4}$ & $\left(1.6 \times 10^{2}\right)$ & $<3300$ \\
\hline $\mathbf{Z r}$ & $2.5 \times 10^{4}$ & $2.5 \times 10^{4}$ & $2.6 \times 10^{4}$ & $2.5 \times 10^{4}$ & $2.2 \times 10^{4}$ & $<910$ & $\left(2.9 \times 10^{3}\right)$ \\
\hline $\mathrm{Br}$ & ND & ND & $<190$ & $<190$ & ND & ND & $<730$ \\
\hline $\mathrm{Cl}$ & ND & ND & $* *$ & $* *$ & ND & ND & $* *$ \\
\hline $\mathbf{F}$ & ND & ND & $* *$ & $* *$ & ND & ND & $* *$ \\
\hline $\mathrm{NO}_{3}$ & ND & ND & $\left(1.1 \times 10^{3}\right)$ & $\left(5.2 \times 10^{2}\right)$ & ND & ND & 56000 \\
\hline $\mathrm{NO}_{2}$ & ND & ND & $* * *$ & $* * *$ & ND & ND & $* * *$ \\
\hline $\mathrm{PO}_{4}$ & ND & ND & $\left(1.1 \times 10^{3}\right)$ & $\left(9.5 \times 10^{2}\right)$ & ND & ND & $<1700$ \\
\hline $\mathrm{SO}_{4}$ & ND & $\mathrm{ND}$ & $\left(1.2 \times 10^{3}\right)$ & $\left(1.2 \times 10^{3}\right)$ & ND & $\mathrm{ND}$ & $8.7 \times 10^{4}$ \\
\hline $\mathbf{N H}_{3}$ & \multicolumn{2}{|c|}{${ }^{++}<38.5$} & \multicolumn{2}{|c|}{${ }^{++}<37.5$} & ND & \multicolumn{2}{|c|}{${ }^{++}<31.7$} \\
\hline $\mathbf{C N}$ & \multicolumn{2}{|c|}{$<0.102$} & \multicolumn{2}{|c|}{$<0.102$} & ND & \multicolumn{2}{|c|}{$<0.102$} \\
\hline Halide $^{+}$ & \multicolumn{2}{|c|}{117} & \multicolumn{2}{|c|}{233} & ND & \multicolumn{2}{|c|}{192} \\
\hline
\end{tabular}

ND indicates the sample was not analyzed for this analyte. Neither a concentration nor a detection limit is available.

() Parentheses indicate analytes that were detected but at concentrations less than 10x the method detection limit.

*Recoveries were not within the specified range for the matrix spikes or matrix spike duplicates for these analytes.

**Neither the concentration nor the detection limits could be determined because of interferences and a base line shift.

**** Interferences and base line shift were observed in analysis of nitrite. Detection limits could not be determined. Although a quantitative analysis could not be made, the results suggest that nitrite was present in the samples.

${ }^{+}$Total halide measurement. This is fluorine, chlorine, bromine, and iodine.

${ }^{++}$These results are to be interpreted as nondetects based on application of the 5x rule to the trip blank. 


\section{WSRC-TR-2001-00109, Revision 1 \\ SRT-RPP-2001-00026, Revision 1 \\ Formerly BNF-003-98-0252}

Primary component concentrations (concentrations $>1000 \mathrm{ppm}$ ) were close to the target values. ${ }^{4}$ The anion concentrations given in Table 5.3 were determined by analysis of the samples that were dissolved by peroxide fusion followed by a water uptake. Because of the dilution factor experienced during dissolution of the the glass waste form (approximately a factor of $0.5 \mathrm{~g}$ to 100 $\mathrm{mL}$ ), detection limits are at least 200 times higher than analyses of a more pristine aqueous solution.

\section{Analysis to Support Permitting}

Results presented in this section are those specified in Table 3 of Reference 1. While four of the volatile organic compounds were detected in the samples, the concentrations (between 3 and 7 $\mu \mathrm{g} / \mathrm{kg}$ ) at which they were detected were below what is typically considered quantitative (less than ten times the detection limit). In addition, two unidentified organic compounds were detected during Method 8270C analyses. These compounds were detected in all samples, process blanks, and field blanks.

\section{Volatile Organic Compounds}

Results presented in this subsection are for the volatile compounds specified in Table 3 of Reference 1. While Method 8260B did show trace levels of four volatile organic compounds were present in one of the samples, the concentrations were below what is commonly considered the lower quantitative limit (below ten times the detection limit). Toluene, 2-methyl-2-propanol, and octamethyl cyclotetrasiloxane were also detected in one of the field blanks. The presence of these compounds is expected to be due to contamination of the sample. Although acetone was only detected in the sample, its presence is also expected to be due to laboratory contamination.

\section{a. Volatile Organic Compounds Measured Using EPA SW-846 Method 8260}

Results from the Method 8260B analysis have been presented in Table 5.4. For Sample 1, no volatile organic compound was detected in these analyses. Although for Sample 2 small concentrations of four volatile compounds were detected, the concentrations were less than 10 times the detection limit. Therefore, the uncertainty associated with these values should be considered to be high. With the exception of acetone (2-propanone), these analytes were also detected in the field blank.

\section{b. Volatile Organic Compounds Measured Using Ion Chromatography}

Results from the ion chromatography analyses for the volatile organic compounds have been reported in Table 5.5. In addition, Table 5.5 shows the results from the process blanks and from the field blanks. These analytes were determined by ion chromatography because determination of these compounds using Method $8260 \mathrm{~B}$ is known to be problematic. Use of ion chromatography is consistent with the QAPjP, the task plan, and discussions held between RPP personnel and SRTC. 
WSRC-TR-2001-00109, Revision 1

SRT-RPP-2001-00026, Revision 1

Formerly BNF-003-98-0252

Table 5.4. Volatile Organic Compound Results $(\mu \mathrm{g} / \mathrm{kg})$ Determined by Method 8260B

("<" indicates an analyte that was not present above the method detection limit. Results

following the "<" are the method detection limits for the analyte indicated.)

\begin{tabular}{|c|c|c|}
\hline & \multicolumn{2}{|c|}{ Sample } \\
\hline & 1 & 2 \\
\hline Ethyl Benzene & $<5$ & $<5$ \\
\hline Styrene & $<5$ & $<5$ \\
\hline cis-1,3-Dichloropropene & $<5$ & $<5$ \\
\hline trans-1,3-Dichloropropene & $<5$ & $<5$ \\
\hline 3-Heptanone & $<10$ & $<10$ \\
\hline $\mathrm{m}$ and $\mathrm{p}$-Xylene & $<5$ & $<5$ \\
\hline Ethylene Dibromide & $<5$ & $<5$ \\
\hline Butane* & ND & $\mathrm{ND}$ \\
\hline 1,3-Butadiene* ${ }^{*}$ & ND & ND \\
\hline Acrolein & $<20$ & $<20$ \\
\hline 3-Chloropropene & $<5$ & $<5$ \\
\hline 1,2-Dichloroethane & $<5$ & $<5$ \\
\hline Propionitrile*** & ND & ND \\
\hline Acrylonitrile & $<5$ & $<5$ \\
\hline 2-Pentanone*** & ND & ND \\
\hline 4-Methyl-2-Pentanone & $<5$ & $<5$ \\
\hline $\mathrm{m}$ and $\mathrm{p}$-Xylene & $<5$ & $<5$ \\
\hline Methylcyclohexane & $<5$ & $<5$ \\
\hline Toluene & $<5$ & $(6.6)$ \\
\hline Chlorobenzene & $<5$ & $<5$ \\
\hline Cyclohexanone & $<10$ & $<10$ \\
\hline n-Pentane & $<5$ & $<5$ \\
\hline Tetrahydrofuran & $<20$ & $<20$ \\
\hline 5-Methyl-2-Hexanone & $<10$ & $<10$ \\
\hline 2-Heptanone & $<10$ & $<10$ \\
\hline n-Hexane & $<5$ & $<5$ \\
\hline Cyclohexane & $<5$ & $<5$ \\
\hline Cyclohexene & $<5$ & $<5$ \\
\hline n-Octane & $<5$ & $<5$ \\
\hline n-Nonane & $<5$ & $<5$ \\
\hline 4-Heptanone & $<10$ & $<10$ \\
\hline n-Propionaldehyde & $<5$ & $<5$ \\
\hline Acetic Acid n-Butyl Ester & $<5$ & $<5$ \\
\hline 1,4-Dioxane & $<100$ & $<100$ \\
\hline 2-Methyl-2-Propenenitrile & $<5$ & $<5$ \\
\hline Tetrachloroethene & $<5$ & $<5$ \\
\hline Acetic Acid Ethyl Ester & $<5$ & $<5$ \\
\hline n-Heptane & $<5$ & $<5$ \\
\hline Cyclopentane*** & ND & $\mathrm{ND}$ \\
\hline trans-1,2-Dichloroethene & $<5$ & $<5$ \\
\hline
\end{tabular}

\begin{tabular}{|c|c|c|}
\hline & \multicolumn{2}{|c|}{ Sample } \\
\hline & 1 & 2 \\
\hline cis-1,2-Dichloroethene & $<5$ & $<5$ \\
\hline Cyclopentane & $<5$ & $<5$ \\
\hline 2-Butenaldehyde & $<1000$ & $<1000$ \\
\hline Carbon Tetrachloride & $<5$ & $<5$ \\
\hline 3-Methyl-2-Butanone** & ND & ND \\
\hline 2-Hexanone & $<5$ & $<5$ \\
\hline Ethyl Alcohol**** & ND & ND \\
\hline 2-Propyl Alcohol*** & ND & ND \\
\hline 2-Propanone (Acetone) ${ }^{\#}$ & $<5$ & $(6.4)$ \\
\hline Chloroform & $<5$ & $<5$ \\
\hline Hexafluoroacetone** & ND & ND \\
\hline n-Propyl Alcohol*** & ND & ND \\
\hline n-Butyl Alcohol & $<50$ & $<50$ \\
\hline Benzene & $<<5$ & $<5$ \\
\hline 1,1,1-Trichloroethane & $<5$ & $<5$ \\
\hline Bromomethane & $<5$ & $<5$ \\
\hline Chloromethane & $<5$ & $<5$ \\
\hline Chloroethane & $<5$ & $<5$ \\
\hline 1-Chloroethene & $<5$ & $<5$ \\
\hline Acetonitrile & $<20$ & $<20$ \\
\hline Dichloromethane & $<<$ & $<5$ \\
\hline Carbon Disulfide & $<5$ & $<5$ \\
\hline Oxirane & $<5$ & $<5$ \\
\hline 1,1-Dichloroethane & $<5$ & $<5$ \\
\hline 1,1-Dichloroethene & $<5$ & $<5$ \\
\hline Dichlorofluoromethane & $<5$ & $<5$ \\
\hline Chlorodifluoromethane & $<5$ & $<<5$ \\
\hline 2-Methyl-2-Propanol ${ }^{\#}$ & $<5$ & $(5.6)$ \\
\hline Trichlorofluoromethane & $<5$ & $<5$ \\
\hline Dichlorodifluoromethane & $<5$ & $<5$ \\
\hline 1,2,2-Trichloro-1,1,2-Trifluoroethane & $<5$ & $<5$ \\
\hline 1,2,-Dichloro-1,1,2,2-Tetrafluoroethane & $<5$ & $<5$ \\
\hline 1,2-Dichloropropane & $<5$ & $<5$ \\
\hline 1-Methylpropyl Alcohol*** & ND & ND \\
\hline 2-Butanone & $<5$ & $<5$ \\
\hline 1,1,2-Trichloroethane & $<5$ & $<5$ \\
\hline 1,1,2-Trichloroethylene & $<5$ & $<5$ \\
\hline 1,1,2,2-Tetrachloroethane & $<5$ & $<5$ \\
\hline o-Xylene & $<5$ & $<5$ \\
\hline Octamethyl Cyclotetrasiloxane ${ }^{* * * *, \#}$ & ND & 3 \\
\hline
\end{tabular}

ND indicates neither a concentration nor a detection limit is available. See additional footnotes for details.

() Parentheses indicate analytes that were detected but at concentrations less than 10x the method detection limit.

*These analytes are gases, and standards could not be prepared. These analytes were monitored for but not seen as TICs.

**Standards for these analytes were not detected at $20 \mathrm{ppm}$. These analytes were monitored for but not seen as TICs.

$* * *$ These analytes were monitored for but not seen as TICs.

*****This analyte was monitored for as a TIC and was detected in one of the samples.

\#Recovery for these analytes was greater than $130 \%$ for the matrix spike or matrix spike duplicate. 


\section{WSRC-TR-2001-00109, Revision 1 \\ SRT-RPP-2001-00026, Revision 1 \\ Formerly BNF-003-98-0252}

Table 5.5. Results (mg/kg) of Volatile Organic Compounds Determined by IC

("<" indicates an analyte that was not present above the method detection limit. Results

following the "<" are the method detection limits for the analyte indicated.)

\begin{tabular}{|c||c|c|c|c|c|c||c|c|}
\hline \multicolumn{1}{|c||}{} & \multicolumn{2}{c||}{ Samples } & \multicolumn{4}{c||}{ Process Blanks } & \multicolumn{2}{c|}{ Field Blank } \\
\hline & $\mathbf{1}$ & $\mathbf{2}$ & $\mathbf{1}$ & $\mathbf{2}$ & $\mathbf{3}$ & $\mathbf{4}$ & $\mathbf{1}$ & $\mathbf{2}$ \\
\hline Triethylamine & $<5.0$ & $<5.0$ & $<5.0$ & $<5.0$ & $<5.0$ & $<5.1$ & $<5.1$ & $<5.0$ \\
\hline Formate & $<1.0$ & $<1.0$ & $<1.0$ & $<1.0$ & $<1.0$ & $<1.0$ & $(2.24)$ & $(2.17)$ \\
\hline Acetate & $<1.0$ & $<1.0$ & $<1.0$ & $(2.65)$ & $<1.0$ & $<1.0$ & $(5.24)$ & $(6.84)$ \\
\hline
\end{tabular}

() Parentheses indicate analytes that were detected but at concentrations less than 10x the method detection limit.

As expected neither triethylamine, formate, nor acetate was detected in the samples. Although for one of the process blanks, a small concentration of acetate was detected, the concentration was less than 10 times the detection limit. Therefore, the uncertainty associated with this value should be considered to be high. The acetate is expected to have been due to contamination although the source is not known.

\section{c. Methanol}

The Method 8015 analysis showed that methanol concentrations were below the detection limit $(0.1 \mathrm{mg} / \mathrm{kg})$ for all samples and blanks except one process blank. This process blank was shown to have $0.21 \mathrm{mg} / \mathrm{kg}$ of methanol. Although this result is too low to be used quantitatively, it is above the detection limit. The methanol is expected to have been due to contamination although the source is not known.

\section{Semivolatile Organic Compounds}

Results presented in this subsection are for the semivolatile organic compounds specified in Table 3 of Reference 1. Results from the Method 8270C analysis and the oxalate determination have been given in Table 5.6. As expected, the target compounds were not detected in the samples. Two unidentified nontarget compounds were detected in all analyses including the process and field blanks. These compounds are expected to have been due to contamination, although the identity of these compounds was not known.

\section{Pesticides}

Results presented in this subsection are for the pesticides specified in Table 3 of Reference 1. Results from the Method 8081 analysis have been given in Table 5.7. As expected, none of these analytes were detected in any of the samples or the blanks. The detection limits were substantially lower for the field blanks because aliquots of the samples were used for matrix spike and matrix spike duplicate analyses. 


\section{WSRC-TR-2001-00109, Revision 1 \\ SRT-RPP-2001-00026, Revision 1 \\ Formerly BNF-003-98-0252}

Table 5.6. Results $(\mu \mathrm{g} / \mathrm{kg})$ of Semivolatile Analyses

("<" indicates an analyte that was not present above the method detection limit. Results following the "<" are the method detection limits for the analyte indicated.)

\begin{tabular}{|c|c|c|c|c|c|}
\hline & \multicolumn{2}{|c|}{ Samples } & \multicolumn{2}{|c|}{ Process Blanks } & \multirow{2}{*}{$\begin{array}{c}\text { Field Blank } \\
-\end{array}$} \\
\hline & 1 & 2 & 1 & 2 & \\
\hline p-Nitrochlorobenzene & $<500$ & $<1500$ & $<490$ & $<500$ & $<490$ \\
\hline 1,4-Dinitrobenzene & $<500$ & $<1500$ & $<490$ & $<500$ & $<490$ \\
\hline 2-Ethyl-1-Hexanol*** & - & - & - & - & 760 \\
\hline Benzyl Alcohol & $<500$ & $<1500$ & $<490$ & $<500$ & $<490$ \\
\hline 4-Methylphenol & $<500$ & $<1500$ & $<490$ & $<500$ & $<490$ \\
\hline 1,4-Dichlorobenzene & $<500$ & $<1500$ & $<490$ & $<500$ & $<490$ \\
\hline Phenol & $<500$ & $<1500$ & $<490$ & $<500$ & $<490$ \\
\hline $\begin{array}{l}\text { Pyridine } \\
\end{array}$ & $<500$ & $<1500$ & $<490$ & $<500$ & $<490$ \\
\hline Di-sec-Octyl Phthalate & $<500$ & $<1500$ & $<490$ & $<500$ & $<490$ \\
\hline n-Dioctyl Phthalate & $<500$ & $<1500$ & $<490$ & $<500$ & $<490$ \\
\hline 1,2,4-Trichlorobenzene & $<500$ & $<1500$ & $<490$ & $<500$ & $<490$ \\
\hline 2,4-Dinitrotoluene & $<500$ & $<1500$ & $<490$ & $<500$ & $<490$ \\
\hline $\mathrm{N}, \mathrm{N}$-Diphenylamine & $<500$ & $<1500$ & $<490$ & $<500$ & $<490$ \\
\hline $\begin{array}{l}\text { Tributyl Phosphate } \\
\end{array}$ & $<500$ & $<1500$ & $<490$ & $<500$ & $<490$ \\
\hline 2,6-Bis(tert-butyl)-4-Methylphenol & $<500$ & $<1500$ & $<490$ & $<500$ & $<490$ \\
\hline Pentachloronaphthalene* & $\mathrm{ND}$ & ND & $\mathrm{ND}$ & $\mathrm{ND}$ & $\mathrm{ND}$ \\
\hline Hexachloronaphthalene* & ND & ND & ND & ND & ND \\
\hline Tetrachloronaphthalene & $<500$ & $<1500$ & $<490$ & $<500$ & $<490$ \\
\hline 4-Methyl-3-Penten-2-one*** & - & - & - & 210 & - \\
\hline Oxalic Acid & $<600$ & $<690$ & $<660$ & $<660$ & $<690$ \\
\hline Benzo(a)pyrene & $<500$ & $<1500$ & $<490$ & $<500$ & $<490$ \\
\hline Dibenz[a,h]anthracene & $<500$ & $<1500$ & $<490$ & $<500$ & $<490$ \\
\hline 1,3-Dichlorobenzene & $<500$ & $<1500$ & $<490$ & $<500$ & $<490$ \\
\hline 1,1-Dimethylhydrazine* & ND & ND & ND & ND & ND \\
\hline Methylhydrazine* & ND & ND & ND & $\mathrm{ND}$ & ND \\
\hline N-Nitroso-N,N-Dimethylamine & $<500$ & $<1500$ & $<490$ & $<500$ & $<490$ \\
\hline Nitric Acid, Propyl Ester & $<500$ & $<1500$ & $<490$ & $<500$ & $<490$ \\
\hline Hexachloroethane & $<500$ & $<1500$ & $<490$ & $<500$ & $<490$ \\
\hline 2-Propenoic Acid* & ND & ND & $\mathrm{ND}$ & ND & ND \\
\hline 2-Methylphenol & $<500$ & $<1500$ & $<490$ & $<500$ & $<490$ \\
\hline Pentachloronitrobenzene (PCNB) & $<500$ & $<1500$ & $<490$ & $<500$ & $<490$ \\
\hline Hexachlorobutadiene & $<500$ & $<1500$ & $<490$ & $<500$ & $<490$ \\
\hline Naphthalene & $<500$ & $<1500$ & $<490$ & $<500$ & $<490$ \\
\hline Pentachlorophenol & $<500$ & $<1500$ & $<490$ & $<500$ & $<490$ \\
\hline 2-sec-Butyl-4,6-Dinitrophenol & $<500$ & $<1500$ & $<490$ & $<500$ & $<490$ \\
\hline 1,1-Biphenyl & $<500$ & $<1500$ & $<490$ & $<500$ & $<490$ \\
\hline 1,2-Dichlorobenzene & $<500$ & $<1500$ & $<490$ & $<500$ & $<490$ \\
\hline Acetophenone & $<500$ & $<1500$ & $<490$ & $<500$ & $<490$ \\
\hline Nitrobenzene & $<500$ & $<1500$ & $<490$ & $<500$ & $<490$ \\
\hline
\end{tabular}

ND indicates neither a concentration nor a detection limit is available. See additional footnotes for details.

*Although these analytes were not detected in the samples, no quantitative determination could be made as to the method detection limit.

**Although not one of the requested compounds, this analyte was monitored for as a TIC and was detected in one of the blanks.

\section{Polychlorinated Biphenyls (PCBs)}

Results presented in this subsection are for the polychlorinated biphenyl (PCB) analyses specified in Table 3 of Reference 1. Results from the Method 8082 analysis have been given in Table 5.8. As expected, none of these analytes were detected in any of the samples or the blanks. The detection limits were substantially lower for the field blanks and the process blanks because aliquots of the samples were used for matrix spike and matrix spike duplicate analyses. 
WSRC-TR-2001-00109, Revision 1

SRT-RPP-2001-00026, Revision 1

Formerly BNF-003-98-0252

Table 5.7. Results $(\mu \mathrm{g} / \mathrm{kg})$ of Pesticide Analyses

("<" indicates an analyte that was not present above the method detection limit. Results following the "<" are the method detection limits for the analyte indicated.)

\begin{tabular}{|c|c|c|c|}
\hline & \multicolumn{2}{|c|}{ Samples } & \multirow{2}{*}{$\begin{array}{c}\text { Field Blank } \\
-\end{array}$} \\
\hline & 1 & 2 & \\
\hline Hexachlorobenzene & $<15$ & $<15$ & $<4.9$ \\
\hline Octachloronaphthalene & $<15$ & $<15$ & $<4.9$ \\
\hline Toxaphene & $<760$ & $<740$ & $<250$ \\
\hline Aldrin & $<7.6$ & $<7.4$ & $<2.5$ \\
\hline alpha-BHC & $<7.6$ & $<7.4$ & $<2.5$ \\
\hline beta-BHC & $<7.6$ & $<7.4$ & $<2.5$ \\
\hline Isodrin & $<15$ & $<15$ & $<4.9$ \\
\hline Dichlorodiphenyl Trichloroethane & $<15$ & $<15$ & $<4.9$ \\
\hline gamma-BHC (Lindane) & $<7.6$ & $<7.4$ & $<2.5$ \\
\hline Dieldrin & $<15$ & $<15$ & $<4.9$ \\
\hline $\begin{array}{l}\text { Endrin } \\
\end{array}$ & $<15$ & $<15$ & $<4.9$ \\
\hline 1,1-Bis(4-Chlorophenyl)-2,2 Dichloroethane & $<15$ & $<15$ & $<4.9$ \\
\hline Heptachlor & $<7.6$ & $<7.4$ & $<2.5$ \\
\hline
\end{tabular}

Table 5.8. Results $(\mu \mathrm{g} / \mathrm{kg})$ of Polychlorinated Biphenyls (PCBs) Analyses ("<" indicates an analyte that was not present above the method detection limit. Results following the "<" are the method detection limits for the analyte indicated.)

\begin{tabular}{|c|c||c|c||c|c||c|}
\hline CAS Number & \multicolumn{1}{|c||}{ Analyte } & \multicolumn{2}{|c||}{ Samples } & \multicolumn{2}{c||}{ Process Blanks } & Field Blank \\
\hline & & $\mathbf{1}$ & $\mathbf{2}$ & $\mathbf{1}$ & $\mathbf{2}$ & - \\
\hline $\mathbf{1 2 6 7 4 - 1 1 - 2}$ & Aroclor-1016 & $<150$ & $<150$ & $<49$ & $<49$ & $<49$ \\
\hline $\mathbf{1 1 1 0 4 - 2 8 - 2}$ & Aroclor-1221 & $<300$ & $<300$ & $<98$ & $<99$ & $<99$ \\
\hline $\mathbf{1 1 1 4 1 - 1 6 - 5}$ & Aroclor-1232 & $<150$ & $<150$ & $<49$ & $<49$ & $<49$ \\
\hline $\mathbf{5 3 4 6 9 - 2 1 - 9}$ & Aroclor-1242 & $<150$ & $<150$ & $<49$ & $<49$ & $<49$ \\
\hline $\mathbf{1 2 6 7 2 - 2 9}-6$ & Aroclor-1248 & $<150$ & $<150$ & $<49$ & $<49$ & $<49$ \\
\hline $\mathbf{1 1 0 9 7 - 6 9 - 5}$ & Aroclor-1254 & $<150$ & $<150$ & $<49$ & $<49$ & $<49$ \\
\hline $\mathbf{1 1 0 9 6 - 8 2}-5$ & Aroclor-1260 & $<150$ & $<150$ & $<49$ & $<49$ & $<49$ \\
\hline $\mathbf{3 7 3 2 7 - 2 3 - 5}$ & Aroclor-1262 & $<150$ & $<150$ & $<49$ & $<49$ & $<49$ \\
\hline $\mathbf{1 1 1 0 0 - 1 4 - 4}$ & Aroclor-1268 & $<150$ & $<150$ & $<49$ & $<49$ & $<49$ \\
\hline
\end{tabular}

\section{Radionuclides}

Radionuclide concentrations have been presented in Table 5.9. Cesium-137, strontium-90, technetium-99 and total beta values were high enough to be quantitative. Other radionuclides were detected at lower concentrations. The results presented in Table 5.9 are similar to results determined at SRTC. Compliance of the waste form characteristics with RPP contract radionuclide specifications is discussed in Reference 4. 


\section{WSRC-TR-2001-00109, Revision 1 \\ SRT-RPP-2001-00026, Revision 1 \\ Formerly BNF-003-98-0252}

Table 5.9. Results (pCi/g) of Radionuclide Analyses

("<" indicates an analyte that was not present above the minimum detectable activity. Results following the "<" are the method detection limits for the analyte indicated.)

\begin{tabular}{|c|c|c|c|c|c|c|c|c|c|c|}
\hline & \multicolumn{4}{|c|}{ Samples } & \multicolumn{4}{|c|}{ Process Blanks } & \multicolumn{2}{|c|}{ Field Blanks } \\
\hline & \multicolumn{2}{|c|}{ Acid } & \multicolumn{2}{|c|}{ Fusion } & \multicolumn{2}{|c|}{ Acid } & \multicolumn{2}{|c|}{ Fusion } & Acid & Fusion \\
\hline & 1 & 2 & 1 & 2 & 1 & 2 & 1 & 2 & - & - \\
\hline Am-241 & (27) & $<25$ & $<25$ & (37) & $<15$ & $<16$ & $<10$ & $<19$ & $<110$ & $<91$ \\
\hline Cs-134 & $<410$ & $<350$ & $<300$ & $<480$ & $<45$ & $<33$ & $<36$ & $<45$ & $<110$ & $<140$ \\
\hline Cs-137 & $1.2 \mathrm{E} 6$ & $1.3 \mathrm{E} 6$ & $1.2 \mathrm{E} 6$ & $1.2 \mathrm{E} 6$ & $<41$ & $<40$ & (33) & $<53$ & $<120$ & $<180$ \\
\hline Co-60 & $2.9 \mathrm{E} 2$ & $3.1 \mathrm{E} 2$ & $3.0 \mathrm{E} 2$ & $2.4 \mathrm{E} 2$ & $<54$ & $<38$ & $<38$ & $<52$ & $<130$ & $<190$ \\
\hline Nb-94 & $<61$ & $<38$ & $<45$ & $<77$ & $<44$ & $<37$ & $<31$ & $<41$ & $<100$ & $<140$ \\
\hline Eu-152 & $<2000$ & $<1500$ & $<1500$ & $<2400$ & $<120$ & $<100$ & $<120$ & $<130$ & $<310$ & $<470$ \\
\hline Eu-154 & $<160$ & $<120$ & $<130$ & $<240$ & $<160$ & $<110$ & $<110$ & $<150$ & $<370$ & $<540$ \\
\hline Eu-155 & $<950$ & $<860$ & $<810$ & $<1300$ & $<86$ & $<86$ & $<110$ & $<89$ & $<240$ & $<390$ \\
\hline Ru-103 & $<740$ & $<530$ & $<580$ & $<940$ & $<45$ & $<33$ & $<36$ & $<47$ & $<110$ & $<150$ \\
\hline Ru-106 (Rh-106) & $<4100$ & $<3700$ & $<3000$ & $<4700$ & $<390$ & $<310$ & $<320$ & $<410$ & $<850$ & $<1400$ \\
\hline Ra-226 & $<850$ & $<740$ & $<630$ & $<1000$ & $<96$ & $(89)$ & $(51)$ & $<96$ & $(2.5 \mathrm{E} 2)$ & $<340$ \\
\hline Total Alpha & $(1.8 \mathrm{E} 2)$ & $(1.6 \mathrm{E} 2)$ & $(2.5 \mathrm{E} 2)$ & (3.7E2) & $<150$ & $<100$ & $<290$ & $<180$ & $<180$ & (4.7E2) \\
\hline Total Beta & $1.0 \mathrm{E} 6$ & 9.9E5 & $1.0 \mathrm{E} 6$ & $1.0 \mathrm{E} 6$ & $(3.5 \mathrm{E} 2)$ & $(2.6 \mathrm{E} 2)$ & $<190$ & $<210$ & $(9.2 \mathrm{E} 2)$ & (2.0E3) \\
\hline Sr-90 (Y-90) & $3.5 \mathrm{E} 3$ & $3.9 \mathrm{E} 3$ & $4.0 \mathrm{E} 3$ & $4.0 \mathrm{E} 3$ & $<200$ & $<170$ & $<180$ & $<190$ & $<680$ & $<820$ \\
\hline Tc-99 & $2.4 \mathrm{E} 3$ & $2.3 \mathrm{E} 3$ & $(1.8 \mathrm{E} 2)$ & $(2.0 \mathrm{E} 2)$ & $<200$ & $<350$ & $<200$ & $<190$ & $<1100$ & $<880$ \\
\hline Np-237 & $<7$ & $<7$ & ${ }^{+}<14$ & $<11$ & $<11$ & $<7.1$ & $<5$ & $<5.5$ & $<36$ & $<32$ \\
\hline Pu-238 & (40) & (33) & $(45)$ & $\left(1.1 \times 10^{2}\right)$ & $<16$ & $<15$ & (21) & (39) & $<100$ & $<32$ \\
\hline Pu-239/240 & (26) & (38) & $(57)$ & (54) & $<8$ & $<10$ & (15) & (14) & $<45$ & $<32$ \\
\hline Pu-241 & $<1900$ & $<1900$ & $<1800$ & $<1700$ & $<1600$ & $<1700$ & $<1500$ & $<1600$ & $<6900$ & $<7900$ \\
\hline Cm-244 & $<8$ & $<24$ & $<29$ & $(56)$ & $<16$ & $<8$ & $<9$ & $<23$ & $<98$ & $<110$ \\
\hline Cm-242 & $<7$ & $<16$ & $<16$ & $<10$ & $<9$ & $<18$ & $<6$ & $<14$ & $<51$ & $<<53$ \\
\hline Nb-94 & $<61$ & $<38$ & $<45$ & $<77$ & $<44$ & $<37$ & $<31$ & $<41$ & $<100$ & $<140$ \\
\hline Se-79* & $<3500$ & $<3500$ & $<3500$ & $<3600$ & $<3500$ & $<3400$ & $<3400$ & $<3500$ & $<13000$ & $<16000$ \\
\hline H-3 & $<2300$ & $<2300$ & $* * *<1.8 \mathrm{E} 4$ & $(2.3 \mathrm{E} 4)$ & $<4.1 \mathrm{E} 3$ & $<480$ & $<6.2 \mathrm{E} 3$ & $<6.6 \mathrm{E} 3$ & $<8600$ & $<1.1 \mathrm{E} 4$ \\
\hline I-129 & $<510$ & $* * *<670$ & $<520$ & $<520$ & $<340$ & $<510$ & $<800$ & $<430$ & $<1400$ & $<1500$ \\
\hline U-234 & (17) & (17) & $(20)$ & $<14$ & $<17$ & $<13$ & $<12$ & $<14$ & $<41$ & $<78$ \\
\hline U-235 & $<8$ & $<8$ & $<7$ & $<11$ & $<11$ & $<13$ & $<>$ & $<14$ & $<41$ & $<53$ \\
\hline U-236 & $<8$ & $<8$ & $<7$ & $<10$ & $<100$ & $<8$ & $<7$ & $<12$ & $<41$ & $<53$ \\
\hline \multirow[t]{2}{*}{ U-238 } & $<11$ & $<8$ & $<7$ & $<9$ & $<9$ & $<11$ & $<7.3$ & $<10$ & $<41$ & $<59$ \\
\hline & \multicolumn{2}{|c|}{1} & \multicolumn{2}{|c|}{2} & \multicolumn{2}{|c|}{1} & \multicolumn{2}{|c|}{2} & \multicolumn{2}{|c|}{ - } \\
\hline C-14** & \multicolumn{2}{|c|}{${ }^{+}<3.85$} & \multicolumn{2}{|c|}{${ }^{+}<7.21$} & \multicolumn{2}{|c|}{$<3.37$} & \multicolumn{2}{|c|}{$<3.82$} & \multicolumn{2}{|c|}{$<3.58$} \\
\hline
\end{tabular}

() Parentheses indicate analytes that were detected but at concentrations less than 10x the method detection limit.

*Carrier recovery for these analytes was low. SRTC personnel who have experience with this method indicated that the recoveries obtained by

BWXT are typical of the method. They were, however, below the acceptable recovery range of 70 to $125 \%$ given in Reference 2 .

**Carbon-14 was measured in the solid glass waste form to avoid potential losses during dissolution processes. Reported as less than due to interferences.

***This result is to be interpreted as a nondetect based on application of the $5 \mathrm{x}$ rule to the method blank.

${ }^{+}$These results were reported as less than due to interferences.

\section{E. Physical Properties}

Results from density determinations have been presented in Table 5.10. The viscosity, total dissolved solids and total suspended solids were not determined on these samples. This is consistent with Reference 1, Reference 2, and Reference 3. Viscosity and solids analyses would not have been applicable to these samples. The density results were close to the expected values $(\sim 2.7 \mathrm{~g} / \mathrm{cc})$. 
WSRC-TR-2001-00109, Revision 1

SRT-RPP-2001-00026, Revision 1

Formerly BNF-003-98-0252

Table 5.10. Results from Density (g/cc) Determination of Envelope A Glass Samples

\begin{tabular}{|c||c|c||c|c|c|}
\hline \multicolumn{1}{|c|}{} & \multicolumn{2}{c||}{ Samples } & \multicolumn{2}{c|}{ Process Blanks } & Field Blanks \\
\hline & $\mathbf{1}$ & $\mathbf{2}$ & $\mathbf{1}$ & $\mathbf{2}$ & - \\
\hline \hline Density & 2.724 & 2.935 & 2.803 & 2.781 & 2.733 \\
\hline
\end{tabular}

\subsection{Discussion}

The title of each section in this chapter was taken from the corresponding table in Reference 1. Titles are not meant to suggest that the designated activities are underway. For example, Section A is titled "Analysis to Support Delisting Petition." At this time, the authors are not involved in efforts toward delisting the low-activity waste forms from the Hanford High-Level Waste tanks.

\section{A. Analyses to Support Delisting Petition}

Analyses were successful at showing that this waste form would meet Land Disposal Requirements. Cyanide concentrations were below 40CFR268 limits, and ignitability tests showed the waste form was not ignitable. Analysis of TCLP leachate showed that the waste form met the Universal Treatment Standard (UTS), and dioxin and furan concentrations were low and the concentrations in the samples were similar to concentrations in the field blank. Additional clarification is given in this section for the TCLP and dioxin and furan analyses.

For the TCLP analyses, barium and mercury matrix spike and matrix spike duplicate recoveries, and silver matrix spike recoveries were low. For mercury and barium, the glass waste form did not contain sufficient quantities to be hazardous, even if all were to be released from the glass. This can be seen using the results from the total metal analyses in Table 5.1.

For silver, the TCLP leachate was more than an order of magnitude below the UTS limit. The matrix spike duplicate and the post spike were both within the required range for metals $(75 \%$ to $125 \%$ ). In addition, the matrix spike was only very slightly lower than the allowable recovery $(74.4 \%)$. Therefore, although the results for silver did not meet the quality control requirements for the matrix spike recovery (74.4\% compared to $75 \%$ ), the leachate silver concentrations were far below the UTS silver limit. As a result, we have a high degree of confidence that the TCLP leachate silver concentration was below the UTS limit.

Two dioxins (1,2,3,4,6,7,8-HpCDD and OCDD) and one furan (OCDF) were detected in the waste form. All three of these were detected in similar or much higher concentrations in all process and field blanks. In addition OCDD was reported in the laboratory's method blank. Because these compounds were found in the blanks, conclusions regarding the concentrations in the samples are not easily reached. One approach would be to consider the results reported for these compounds as the maximum possible concentrations. Another approach would be to apply the CLP 5x rule to the blanks. The 5x rule would indicate that the sample results are below the resulting detection limits. 
WSRC-TR-2001-00109, Revision 1

SRT-RPP-2001-00026, Revision 1

Formerly BNF-003-98-0252

\section{B. Analyses to Support Characterization of Tank Waste Samples}

With the exception of fluoride, chloride, and nitrite the analyses were successful at determining the concentration or a method detection limit for each of the species specified in Table 3 of Reference 1. These results have been given in Table 5.3. The value given for bismuth is suspect because the bismuth recovery in the matrix spike was only $38 \%$.

During ion chromatography, matrix effects apparently caused the baseline to shift such that a determination could not be made as to whether fluoride or chloride was present in the samples. In addition, although nitrite appeared to be present, a determination could not be made as to the concentration of nitrite in the samples. SRTC will work with BWXT to determine whether the IC conditions can be adjusted so that future samples can be analyzed without such interferences.

\section{Analyses to Support Permitting}

With the exception of a few of the semivolatile compounds, the analyses were successful at showing that if present, the concentrations of species specified in Table 3 of Reference 1 were very low. Although these species are not expected to have survived the vitrification process, the analytical methods used could not provide information on the following three compounds: 2propenoic acid, 1,1-dimethylhydrazine and methylhydrazine.

Although most of the volatile organic compound concentrations were below the detection limits, very low concentrations (less than $7 \mu \mathrm{g} / \mathrm{kg}$ ) were reported for three volatile organic compounds (See Table 5.4). Because these three compounds (toluene, 2-methyl-2-propanol, and octamethyl cyclotetrasiloxane) were also detected in one of the field blanks, their presence was expected to have been due to contamination of the samples. Because these compounds were found in the blanks, conclusions regarding the concentrations in the samples are not easily reached. One approach would be to consider the results reported for these compounds as the maximum possible concentrations. Another approach would be to apply the CLP 5x rule to the blanks. The $5 x$ rule would indicate that the sample results are below the resulting detection limits. Although acetone was not reported in the blanks, its presence on the sample is also expected to have been due to contamination.

Twelve of the compounds listed in Table 5.4 were monitored for as tentatively-identified compounds (TICs). These compounds have been noted in Table 5.4. Although calibration curves could not be generated for these compounds, the detection limit for these compounds is expected to have been similar to the other volatile organic compounds (5 to $1000 \mu \mathrm{g} / \mathrm{kg}$ ). 


\section{WSRC-TR-2001-00109, Revision 1 \\ SRT-RPP-2001-00026, Revision 1 \\ Formerly BNF-003-98-0252}

Concentrations of most semivolatile compounds specified in Reference 1 were shown to be below the analytical method detection limits (See Table 5.6). Detection limits were not reported for four of the specified compounds. Standards for pentachloronaphthalene and hexachloronaphthalene could not be obtained. Analysis for tetrachloronaphthalene or octachloronaphthalene did not show fragmentation patterns typical for this family of compounds.

At the BWXT facility, analytical difficulties for the Envelope A samples may have precluded the laboratory's ability to detect three semivolatile compounds, 2-propenoic acid, 11dimethylhydrazine and methylhydrazine. Solutions to these difficulties have been proposed, and future shipments are expected to be analyzed successfully. Problems associated with 2propenoic acid may have been due to the conditions at which the GC column is being operated. In addition, Method 8270C does not appear to be applicable to measuring 1,1-dimethylhydrazine and methylhydrazine. For future analyses, BWXT has recommended use of another GC-MS method.

In addition to the compounds specified in Reference 1, analyses show other semivolatile compounds to be present in these samples and in the blanks. In all samples and blanks, two unidentified compounds were reported. Because these were also reported in the laboratory's method blank at similar concentrations, the source of these compounds was assumed to be contamination. Because these compounds were found in the blanks, conclusions regarding the concentrations in the samples are not easily reached. One approach would be to consider the results reported for these compounds as the maximum possible concentrations. Another approach would be to apply the CLP 5x rule to the blanks. The 5x rule would indicate that the sample results are below the resulting detection limits. Additional TICs were reported for one of the process blanks and one of the field blanks (See Table 5.6).

Pesticide and PCB analyses showed none of the compounds to be present at concentrations above the method's detection limits. In addition validation of these analyses showed no additional uncertainty to be associated with the results. Although the continuing calibration for octachloronaphthalene was beyond $15 \%$ is some cases, the analysis met the SW-846 protocol and specification of the project QAPjP.

\section{Radionuclides}

The radionuclide analyses were successful at providing results for all species specified in Table 4 of Reference 1. Results for selenium-79 have been included; however the detection limits for this species were based on standard analyses that were subject to poor analyte recoveries. Carbon-14 results were reported as maximum possible concentration in sample because of interferences. Tritium was also reported as maximum possible concentration because of the presence of contamination in the laboratory's method blank. 


\section{E. Physical Properties}

The measured glass waste form densities were similar to densities determined for glass waste forms made with nonradioactive simulants of the Tank AN-103 supernate. The difference between the two duplicates was slightly higher than expected. This variation may have been due to limitations on producing small quantities of a glass waste form, and sampling.

\subsection{Conclusions}

The Envelope A glass waste form has been shown to meet the requirements for disposal as a "nonhazardous", non-TRU waste form. Specifically, leachates from the TCLP showed the waste form met Universal Treatment Standards for RCRA metals, and radionuclide analyses showed that the waste form would not need to be handled as transuranic waste. In addition, analysis of organic species indicated the few organic species detected were also found at similar concentrations in the blanks.

Although three of the semivolatile organic analytes could not be measured directly, results for the other semivolatile organic analytes suggest that these three compounds also were not present in the glass waste form at detectable concentrations. Results from analysis of the other organic compounds confirmed that although organic compounds may be present in the melter feed, vitrification conditions (very high temperatures) are such that the organic compounds would not be in the glass waste form.

\subsection{References}

1. Johnson, M. E., "TWRS-P Contract No. DE-AC06-96RL13308-W375-Analysis of Evaporator Condensates, Non-Condensable Fraction, and Concentrate, Melter Off-Gas Condensate and Non-Condensable Fraction, ILAW Glass, and ILAW Glass Leachate," BNFL Inc. Document Number 000183, October 5, 1998.

2. Su-Coker, J., "Quality Assurance Project Plan for Testing Programs: Savannah River Technology (SRTC), Pacific Northwest National Laboratory (PNNL)," BNFL Inc. Document Number QP-W375-EN00002, Revision 0, June 7, 1999.

3. Ferrara, D. M., Groseclose, R. S., Ray, R. J., Crawford, C. L., and Calloway, T. B., "Task Technical, Analytical Study, and Quality Assurance Plan in Support of BNFL Part B," WSRC Document Number BNF-003-98-0082, Revision 0, March 1, 2000.

4. Crawford, C. L., Ferrara, D. M., Schumacher, R. F., and Bibler, N. E., "Crucible-Scale Active Vitrification Testing Envelope A, Tank 241-AN-103," WSRC Document Number WSRC-TR-2000-00322, Revision 1, June 15, 2001. 
WSRC-TR-2001-00109, Revision 1

SRT-RPP-2001-00026, Revision 1

Formerly BNF-003-98-0252

5. Ferrara, D. M., Ray, R. J., and Crawford, C. L., "Data Package from Analysis of a Hanford Envelope A Radioactive Glass Waste Form," WSRC Document Number BNF-003-980274, Revision 0, May 31, 2000.

\section{Appendix}

\section{Abbreviated Table of Contents for Data Package (BNF-003-98-0274)}

Volume 1. Cover Letter

Copy of Pages from WSRC Laboratory Notebook WSRC-NB-2000-00060

Spreadsheets-Conversion from Mass per Volume to Mass per Mass

Report of Analytical Data Validation of Regulatory Analyses-Envelope A

Volume 2. Southwest Research Institute SDG139862 Dioxin Analysis (and Furans)

Volume 3. Southwest Research Institute SDG139991-Volatile Analysis (Method 8015) Southwest Research Institute SDG140002-Volatile Analysis (Method 8260) Southwest Research Institute SDG140013 Formate, Acetate, Triethylamine

Volume 4. Babcock and Wilcox SDG0003008-Density, Ignitability, $\mathrm{CN}, \mathrm{NH}_{3}$, Halide Babcock and Wilcox SDG0003028-Semivolatiles (Method 8270) Babcock and Wilcox SDG0003008-Pesticides (Method 8081)

Babcock and Wilcox SDG0003008-PCBs (Method 8082)

Volume 5. Babcock and Wilcox SDG0003008-TCLP Metals (Method 1311) Babcock and Wilcox SDG0003008-Miscellaneous Metals (Method 6010) Babcock and Wilcox SDG0003008-Carbon-14 (Undissolved Samples)

Volume 6. Babcock and Wilcox SDG0003028-Total Metals (Method 6010 and 7471) Babcock and Wilcox SDG0003028-Anions (Method 9056)

Volume 7. Babcock and Wilcox SDG0003028-Radionuclides (Front Material) Babcock and Wilcox SDG0003028-Radionuclides (Case Narrative) Babcock and Wilcox SDG0003028-Radionuclides (C of C/Sample Receipt) Babcock and Wilcox SDG0003028-Radionuclides (Results Summaries) Babcock and Wilcox SDG0003028-Radionuclides (Initial Calibration Data) Babcock and Wilcox SDG0003028-Radionuclides (Continuing Calibration Data)

Volume 8. Babcock and Wilcox SDG0003028-Radionuclides (Data-Gamma PHA) Babcock and Wilcox SDG0003028-Radionuclides (Data-Np, Pu, Am, Cm) 
WSRC-TR-2001-00109, Revision 1

SRT-RPP-2001-00026, Revision 1

Formerly BNF-003-98-0252

Volume 9. Babcock and Wilcox SDG0003028-Radionuclides (Data-Uranium)

Babcock and Wilcox SDG0003028-Radionuclides (Data-Carbon/Tritium)

Babcock and Wilcox SDG0003028-Radionuclides (Data-Selenium)

Babcock and Wilcox SDG0003028-Radionuclides (Data-Alpha and Beta)

Babcock and Wilcox SDG0003028-Radionuclides (Data-Strontium)

Babcock and Wilcox SDG0003028-Radionuclides (Data-Iodine)

Babcock and Wilcox SDG0003028-Radionuclides (Data-Technetium) 